\title{
THERAPEUTIC ASSESSMENT OF N-FORMYL-METHIONYL-LEUCYL- PHENYLALANINE (fMLP) IN REDUCING PERIPROSTHETIC JOINT INFECTION
}

\author{
J.L. Hamilton ${ }^{1,2}$, M.F. Mohamed ${ }^{2}$, B.R. Witt ${ }^{1}$, M.A. Wimmer ${ }^{1,2}$ and S.H. Shafikhani ${ }^{2,3,4, *}$ \\ ${ }^{1}$ Department of Orthopedic Surgery, Rush University Medical Center, Chicago, IL 60612-3806, USA \\ ${ }^{2}$ Department of Internal Medicine, Rush University Medical Center, Chicago, IL 60612-3806, USA \\ ${ }^{3}$ Microbial Pathogens and Immunity, Rush University Medical Center, Chicago, IL 60612-3806, USA \\ ${ }^{4}$ Cancer Center, Rush University Medical Center, Chicago, IL 60612-3806, USA
}

\begin{abstract}
Despite many preventive measures, including prophylactic antibiotics, periprosthetic joint infection (PJI) remains a devastating complication following arthroplasty, leading to pain, suffering, morbidity and substantial economic burden. Humans have a powerful innate immune system that can effectively control infections, if alerted quickly. Unfortunately, pathogens use many mechanisms to dampen innate immune responses. The study hypothesis was that immunomodulators that can jumpstart and direct innate immune responses (particularly neutrophils) at the surgical site of implant placement would boost immune responses and reduce PJI, even in the absence of antibiotics.

To test this hypothesis, $N$-formyl-methionyl-leucyl-phenylalanine (fMLP) (a potent chemoattractant for phagocytic leukocytes including neutrophils) was used in a mouse model of PJI with Staphylococcus aureus (S. aureus). Mice receiving intramedullary femoral implants were divided into three groups: i) implant alone; ii) implant + S. aureus; iii) implant + fMLP + S. aureus.

fMLP treatment reduced S. aureus infection levels by $\sim 2$-Log orders at day 3. Moreover, fMLP therapy reduced infection-induced peri-implant periosteal reaction, focal cortical loss and areas of inflammatory infiltrate in mice distal femora at day 10. Finally, fMLP treatment reduced pain behaviour and increased weight-bearing at the implant leg in infected mice at day 10.

Data indicated that fMLP therapy is a promising novel approach for reducing PJI, if administered locally at surgical sites. Future work will be toward further enhancement and optimisation of an fMLP-based therapeutic approach through combination with antibiotics and/or implant coating with fMLP.
\end{abstract}

Keywords: Periprosthetic joint infection, surgical site infection, Staphylococcus aureus, neutrophil, immunomodulator, $N$-formyl-methionyl-leucyl-phenylalanine.

*Address for correspondence: Sasha H. Shafikhani, Department of Medicine, Division of Hematology, Oncology and Cell Therapy, Department of Microbial Pathogens and Immunity, Cancer Center, Rush University Medical Center, 1735 W. Harrison Street, Chicago, IL 60612-3806, USA.

Telephone number: +13129421368 Email: Sasha_Shafikhani@rush.edu

Copyright policy: This article is distributed in accordance with Creative Commons Attribution Licence (http://creativecommons.org/licenses/by-sa/4.0/).

\begin{tabular}{|c|c|c|c|}
\hline & List of Abbreviations & fMLP & $\begin{array}{l}N \text {-formyl-methionyl-leucyl- } \\
\text { phenylalanine }\end{array}$ \\
\hline AMP & antimicrobial peptide & FPR & formyl peptide receptor \\
\hline ANOVA & analysis of variance & H\&E & haematoxylin and eosin \\
\hline BLI & bioluminescence imaging & ICC & intraclass correlation \\
\hline CFU & colony-forming unit & K-wire & Kirschner wire \\
\hline $\mathrm{CI}$ & confidence interval & $\mathrm{MPO}$ & myeloperoxidase \\
\hline DMSO & dimethyl sulphoxide & NETs & neutrophil extracellular traps \\
\hline EDTA & ethylenediaminetetraacetic acid & NIH & National Institutes of Health \\
\hline fMLF & $N$-formyl-methionyl-leucyl- & PBS & phosphate-buffered saline \\
\hline & phenylalanine & PJI & periprosthetic joint infection \\
\hline
\end{tabular}




$\begin{array}{ll}\text { PRRs } & \text { pattern recognition receptors } \\ \text { PWT } & \text { paw withdrawal threshold } \\ \text { ROI } & \text { region of interest } \\ \text { ROS } & \text { reactive oxygen species } \\ \text { S. aureus } & \text { Staphylococcus aureus } \\ \text { SEM } & \text { standard error of the mean } \\ \text { SSI } & \text { surgical site infection } \\ \text { TSB } & \text { tryptic soy broth } \\ \mu C T & \text { micro-computed tomography }\end{array}$

\section{Introduction}

Approximately 1-2 \% of patients with primary knee and hip replacement and about 3-6 \% of patients with revision knee and hip replacement develop a PJI (Izakovicova et al., 2019; Parvizi et al., 2017). Estimated risk of PJI can be over $20 \%$ in patients with a combination of demographic, surgical (e.g. prior procedure) and/or comorbidity risk factors (e.g. diabetes) (Tan et al., 2018). Moreover, PJI cases are projected to rise significantly within the next two decades due to increased number of joint replacements resulting from increased life expectancy and greater expectations of mobility in the elderly (Izakovicova et al., 2019; Kurtz et al., 2007). This alarming scenario occurs despite many prevention strategies that have been implemented to prevent SSI, including surgical hand antisepsis, reduction of foot traffic in and out of the operating room, use of intraoperative skin antiseptic agents, perioperative glycaemic control, appropriate selection of surgical dressings and prophylactic antibiotics (Allegranzi et al., 2016; Anesi et al., 2017; Bratzler et al., 2004; Campbell et al., 2014; Corona and Singer, 2010; Edmiston et al., 2013; Greif et al., 2000; Kamath et al., 2016; Khoshbin et al., 2015; Kroin et al., 2015; Kroin et al., 2016; Lindsay et al., 2011; Panahi et al., 2012; Parvizi et al., 2017; Sewick et al., 2012; Sidhwa and Itani, 2015; Stannard et al., 2012).

Although multiple bacterial pathogens have been associated with PJIs, S. aureus is often reported as the most common cause, accounting for approximately 13-44 \% of all PJIs (Aggarwal et al., 2014; Manning et al., 2020; Pulido et al., 2008; Tsai et al., 2019). Treatments for PJIs include long courses of antibiotics, debridement of infected tissue and implant removal and replacement (Pelt et al., 2014; Segawa et al., 1999). However, antibiotic use is associated with emergence of antibiotic resistance, gut dysbiosis, increased risk of Clostridium difficile infection, organ cytotoxicity and allergic reactions, and the success rates after these treatments are abysmal, often ranging between 50 to 70 \% (Becattini et al., 2016; Jakobsson et al., 2010; Korpela et al., 2016; Langdon et al., 2016; Pelt et al., 2014; Sampson et al., 2016; Segawa et al., 1999; Yassour et al., 2016). There can be devastating consequences for patients that acquire a PJI, including amputation, arthrodesis, antibiotic-induced organ cytotoxicity or even death (Pelt et al., 2014; Segawa et al., 1999). In addition, patients with a PJI have also an increased risk of developing additional morbidities, such as deep-vein thrombosis and pulmonary embolism (Lieberman and Hsu, 2005). These dismal outcomes underscore the need for new approaches to reduce and to treat PJIs.

The human innate immune system can recognise invading pathogens as "non-self" and mobilise its plethora of defences to protect the organism against them (Brubaker et al., 2015; Guo et al., 2015; Janeway and Medzhitov, 2002; Kawai and Akira, 2011; Martinon et al., 2009; Schroder and Tschopp, 2010; Takeuchi and Akira, 2010). Recognition of microbial pathogens by PRRs sets in motion multiple signalling cascades that culminate in the production of proinflammatory cytokines, which recruit effector innate immune leukocytes, particularly neutrophils; those, in turn, destroy invading pathogens by various direct or indirect mechanisms such as phagocytosis, bursts of ROS, AMP production and NETs (Brinkmann et al., 2004; Dovi et al., 2004). Unfortunately, pathogens have evolved various mechanisms to dampen innate immune responses, blocking production of pro-inflammatory cytokines as well as inducing cell death and blocking proliferation in target host cells (Faure et al., 2014; Hornef et al., 2002; Lai et al., 2009; Mohamed et al., 2021; Shafikhani and Engel, 2006; Shafikhani et al., 2008; Tolle et al., 2015; Wood et al., 2015a; Wood et al., 2015b). The study hypothesis was that local administration of immunomodulators that can accelerate and direct innate immune leukocyte responses (particularly neutrophils) toward the site of the surgically placed implant would enhance the immune responses toward infection and be effective in reducing PJI, even in the absence of prophylactic antibiotics.

To enhance local immune responses at the time of surgery, fMLP (also known as fMLF) was locally administered at the time of implant surgery in an established PJI mouse model (Bernthal et al., 2010; Bernthal et al., 2014; Hegde et al., 2017a; Thompson et al., 2018). fMLP is a naturally occurring formyl peptide. Formyl peptides are released at injured tissues, such as surgical sites, and invading bacterial pathogens (Li et al., 2016; Raoof et al., 2010). fMLP was chosen because it is a potent chemoattractant for neutrophils and other inflammatory leukocytes (Balazovich et al., 1996; Derian et al., 1995; Madianos et al., 2005; Panaro and Mitolo, 1999; Sabroe et al., 2003). In addition, fMLP interaction with FPR chemokine receptors also activates bactericidal functions in neutrophils, such as superoxide and ROS production, phagocytosis and degranulation (Devosse et al., 2009; Dorward et al., 2015; Sengeløv et al., 1994).

\section{Materials and Methods}

\section{Animal experiments}

The study was approval by the Rush University Medical Center Institutional Animal Care and Use Committee (IACUC No: 19-623). All procedures 
complied strictly with the standards for care and use of animal subjects as stated in the Guide for the Care and Use of Laboratory Animals (Institute of Laboratory Animal Resources, National Academy of Sciences, Bethesda, MD, USA). C57BL/6J mice were obtained from The Jackson Laboratory. These mice were allowed to acclimate to the environment for 1 week prior to performing the experiments.

\section{Intra-articular injection}

To demonstrate that fMLP was capable of mobilising and directing neutrophil response in the knee joint even in the absence of infection and/or injury, 12-week-old C57BL/6J mice received local intraarticular injection of fMLP (Sigma-Aldrich, F3506) or vehicle control at the right-knee joint. Prior to injection, right hindlimbs were shaved and disinfected using $70 \%$ ethanol followed by iodine. fMLP was prepared at a concentration of $1 \mu \mathrm{g} / \mu \mathrm{L}$ in a solution of $25 \%$ DMSO and $75 \%$ PBS. Vehicle control was a $5 \mu \mathrm{L}$ solution of $25 \%$ DMSO and $75 \%$ PBS. Mice were anaesthetised using $2 \%$ isoflurane. A total of $5 \mu \mathrm{L}$ of fMLP solution or vehicle control was injected into the right hindlimb knee joint using a $5 \mu \mathrm{L}$ Hamilton ${ }^{\circledR}$ syringe (Hamilton, 7634-01) and 27-Gauge needle, as previously described (Nagao et al., 2017). The dosing of $5 \mu \mathrm{g}$ of fMLP was chosen based on its maximum solubility in vehicle solution and maximum volume of solution that could be injected into the knee-joint space. The syringe needle was applied to the intra-articular space directly through the patellar ligament with the knee flexed at a $90^{\circ}$ angle and needle administration perpendicular to the apex of the flexed knee. A total of $n=5$ mice received fMLP and a total of $n=5$ mice received vehicle control. Mice were evaluated for local neutrophil response at the knee joint using in vivo BLI at $2 \mathrm{~h}$ and $6 \mathrm{~h}$ post injection. Mice were imaged using BLI under $2 \%$ isoflurane anaesthesia.

\section{Preparation of bacteria}

A bioluminescent $S$. aureus (Xen36 S. aureus; PerkinElmer ${ }^{\circledR}$ ) was used that was derived from parental strain S. aureus ATCC 49525 (Wright). This strain has been used and validated in mouse PJI models (Bernthal et al., 2010; Bernthal et al., 2014; Carli et al., 2017; Hegde et al., 2017a). Xen36 S. aureus has been genetically modified to express the modified Photorhabdus luminescens IuxABCDE operon, which encodes a luciferase enzyme, on the native plasmid, enabling this strain to produce a bioluminescent signal. Bacteria were incubated in TSB overnight on the day prior to surgery. On the day of surgery, Xen36 $S$. aureus was diluted in TSB to a spectrophotometer absorbance measurement of $600 \mathrm{~nm}$ at an optical density of 0.5 (against a TSB blank). This was equivalent to $\sim 1.0 \times 10^{8} \mathrm{CFU} / \mathrm{mL}$ of $S$. aureus. This solution was further diluted to $5 \times 10^{5} \mathrm{CFU} / \mathrm{mL}$ in PBS and kept on ice. At the time of surgery, dropwise inoculation of $2 \mu \mathrm{L}$ of $5 \times 10^{5} \mathrm{CFU} / \mathrm{mL}$ in PBS at the open knee-joint surgical site using a $5 \mu \mathrm{L}$ Hamilton $^{\circledR}$ syringe provided $1 \times 10^{3} \mathrm{CFU}$ at the knee joint.

\section{Mouse model of PJI}

To show that an fMLP immunomodulator could reduce PJI, an established PJI model with bioluminescent $S$. aureus was used, as described previously (Bernthal et al., 2010; Carli et al., 2017; Hegde et al., 2017a). Briefly, $2 \mathrm{~d}$ prior to surgery, the ventral and lateral surface of the right hindlimb of 12-week-old C57BL/6J mice were shaved. To ensure additional removal of hair, a hair-removal spray was used. The day prior to surgery, mice underwent baseline testing for BLI, pain behaviour, weight-bearing and weight. The day prior to surgery, all non-sterilised instruments and implant material were autoclaved in self-sealing autoclave pouches. On the day of surgery, mice were anaesthetised using a mixture of ketamine $(90 \mathrm{mg} /$ $\mathrm{kg}$ ) and xylazine $(4.5 \mathrm{mg} / \mathrm{kg})$. The right leg was disinfected using $70 \%$ ethanol followed by iodine. Using aseptic technique and using a dissection microscope (Zeiss, Stemi 508), a skin incision over the right knee was performed followed by a medial parapatellar arthrotomy. Incisions were performed using a Micro Knives sterile scalpel (10315-12, Fine Science Tools, Foster City, CA, USA). To expose the femoral condyles, lateral displacement of the quadriceps patellar complex was performed. The intercondylar notch was located; a 25-Gauge syringe needle attached to a $3 \mathrm{~mL}$ syringe was used to penetrate the intercondylar notch and ream the distal intramedullary canal at a distance of approximately $10 \mathrm{~mm}$. An orthopaedic-grade stainless steel K-wire (diameter $0.6 \mathrm{~mm}$; DePuy Synthes) was surgically placed in a retrograde fashion into the intramedullary canal with assistance of a Pin Holder (Fine Sciences Tools, 26018-17). The distal aspect of the K-wire was cut to a length of approximately $11 \mathrm{~mm}$ with a wire cutter leaving approximately $1 \mathrm{~mm}$ protruding into the joint space.

With the open knee-joint surgical site and implant exposed, in the fMLP group, mice received a local intra-articular dose of $5 \mu \mathrm{g}$ of fMLP in a $5 \mu \mathrm{L}$ solution (25\% DMSO and $75 \%$ PBS). This was the fMLP dose previously used for intra-articular injection at the healthy mouse knee-joint to substantially increase local neutrophil activity (discussed in the Results section). In the control groups, mice received $25 \%$ DMSO/75 \% PBS solution as vehicle control. A $5 \mu \mathrm{L}$ Hamilton $^{\circledR}$ syringe was used to drop the solution into the exposed knee-joint space. The solution was left untouched at the knee joint for 5 min to enhance its absorption. This was followed by administration of $1 \times 10^{3}$ CFU $S$. aureus in a $2 \mu \mathrm{L}$ solution of PBS or PBS control with use of separate $5 \mu \mathrm{L}$ Hamilton $^{\circledR}$ syringes into the exposed knee-joint space and on top of the implant. Administration of this and/or similar amounts of bacteria into the exposed knee-joint space has been described previously in a mouse PJI model with S. aureus (Bernthal et al., 2010; Bernthal et al., 
2014; Carli et al., 2017; Hegde et al., 2017b). Then, the exposed knee-joint space was again left untouched for 5 min to enhance absorption of the solution at the knee joint. Following absorption, the quadriceps complex was reduced back to midline. The knee-joint capsule was closed using 6-0 VICRYL sutures (Ethicon). Then, skin was closed using 6-0 PROLENE sutures (Ethicon). Mice were placed on a warming blanket for recovery following surgery. For analgesia, mice received subcutaneous buprenorphine $(0.1 \mathrm{mg} / \mathrm{kg})$ every $12 \mathrm{~h}$ for a duration of $48 \mathrm{~h}$ following surgery. Following surgery, living mice received assessments through BLI at days 1, 3, 5, 7 and 10; and von Frey filament testing, weight-bearing testing and body weight assessment at day 10. Mice were sacrificed at day 10 for $\mu \mathrm{CT}$ assessment and histological analysis. In a parallel study, mice were sacrificed at day 3 for infection assessment by bacteria count of the periimplant knee-joint tissue and implant, using CFU analysis. In total, 35 mice received femoral implant placement in the PJI model: $n=5$ implant control, $n=15 \mathrm{implant}+S$. aureus, $n=15 \mathrm{implant}+\mathrm{fMLP}+S$. aureus. A total of $n=6$ mice in each of the two infected groups were sacrificed at day 3 for CFU analysis; these mice were assessed through BLI up to day 3. The remaining mice ( $n=5$ implant, $n=9$ implant $+S$. aureus, $n=9$ implant $+\mathrm{fMLP}+S$. aureus) were assessed through BLI up to day 10 as well as von Frey filament testing (day 10), weight-bearing (day 10) and body weight measurement (day 10). Then, these mice were sacrificed at day 10 for gross morphological assessment, $\mu \mathrm{CT}$ analysis and histological analysis.

\section{BLI}

IVIS ${ }^{\circledR}$ Lumina II In Vivo Imaging System (PerkinElmer $\left.{ }^{\circledR}\right)$ was used to track neutrophil activity at the knee joint as well as for quantification of bacterial abundance at the knee joint. For the assessment of neutrophil response in mice receiving knee injection of fMLP or vehicle control, BLI was performed at baseline prior to injection as well as at $2 \mathrm{~h}$ and $6 \mathrm{~h}$ post injection. $8 \mathrm{~min}$ prior to each imaging time-point, mice received intra-peritoneal injection of $100 \mathrm{mg} / \mathrm{kg}$ of luminol (Sigma-Aldrich, A4685) in PBS solution. Luminol is a chemiluminescent compound that produces a bioluminescent signal in the presence of ROS catalysed by MPO in neutrophils and has been used previously as a measure of neutrophil activity in the joints and subcutaneous tissue of mice (Gross et al., 2009; Tseng and Kung, 2013).

In the mouse PJI model, BLI to quantify bioluminescent signal from bioluminescent $S$. aureus Xen 36 was performed at baseline (prior to surgery) as well as at days 1, 3, 5, 7 and 10 post-surgery. There is direct correlation between Xen36 S. aureus light intensity and quantified tissue and implant bacterial burdened measured by CFU count at the site of the implant and surrounding tissue (Bernthal et al., 2010). In all BLI experiments, exposure time was performed for a total of $5 \mathrm{~min}$. A standard circular
ROI with a diameter spanning from the distal $1 / 4^{\text {th }}$ of the femur and proximal $1 / 4^{\text {th }}$ of the tibia/fibula was used. The ROI used for both assessment of neutrophil activity and bacterial bioluminescent signal using BLI are represented as red outlines in Fig. 1a and Fig. 2a, respectively. Emission intensity at the ROI over time was quantified using mean maximum flux (photons $/ \mathrm{s} / \mathrm{cm}^{2} / \mathrm{sr}$ ). Mice were imaged using BLI under $2 \%$ isoflurane anaesthesia. A total of $n=15$ mice in each of the two infected groups were analysed with BLI. For CFU analysis, $n=6$ mice in each of the infected groups were sacrificed at day 3 and only received BLI up to day 3 . The remaining mice $(n=5$ implant, $n=9$ implant $+S$. aureus, $n=9$ implant $+\mathrm{fMLP}+S$. aureus) received BLI assessment up to day 10. BLI images for each group were selected for representation of mean values of mean maximum flux (photons $/ \mathrm{s} / \mathrm{cm}^{2} / \mathrm{sr}$ ) at the ROI.

\section{Infection burden assessment by CFU analysis at knee joint and implant}

A subset of $n=6$ mice in each of the infected groups ( $n=6 \mathrm{implant}+S$. aureus, $n=6 \mathrm{implant}+\mathrm{fMLP}+S$. aureus) underwent CFU analysis following BLI at day 3 post-surgery. Briefly, mice were sacrificed at day 3 post-infection and the distal $1 / 4^{\text {th }}$ of the femur and the proximal $1 / 4^{\text {th }}$ of the tibia/fibula were cut and harvested to isolate the knee joint. Skin was removed from the harvested knee joint and the remaining bone and soft tissue was used for CFU analysis. The implant was removed in an anterograde fashion from the cut end of the femur. Bacterial loads from processed tissue and implants were determined using serial dilution and plating as previously described (Goldufsky et al., 2015; Kroin et al., 2015; Kroin et al., 2012; Kroin et al., 2016; Kroin et al., 2018). Samples were diluted in PBS to produce dilutions ranging from $10^{-1}$ to $10^{-5}$ within 96 -well microplates. Aliquots of $5 \mu \mathrm{L}$ were spot-plated at $10^{0}-10^{-5}$ on tryptic soy agar plates and incubated at $37^{\circ} \mathrm{C}$ for $24 \mathrm{~h}$. CFU counts were quantified the following day. Bacterial burden was assessed as CFU/g tissue for knee joint and surrounding tissue. Bacterial burden for tissue implant was assessed as CFU/implant.

\section{Gross morphology analysis}

Following sacrifice, mice underwent further imaging with the aid of a Zeiss (Stemi 508) dissection stereomicroscope. Gross morphology was assessed for all mice that were sacrificed at day 10 postsurgery ( $n=5$ implant, $n=9 \mathrm{implant}+S$. aureus, $n=9$ implant + fMLP $+S$. aureus). Images were acquired following skin incision, to image the knee-joint capsule, and the knee-joint capsule was opened to image the distal femur and implant. Knee capsule width measurements were performed using ImageJ (NIH) using a known reference length from each image. Images of gross morphology for each group were selected as average representatives within each group. 


\section{Histological analysis}

The distal aspects of femora and surrounding tissues were fixed in $4 \%$ formaldehyde for $3 \mathrm{~d}$ at $4{ }^{\circ} \mathrm{C}$ and stored in $70 \%$ ethanol at $4{ }^{\circ} \mathrm{C}$ for $\mu \mathrm{CT}$ analysis. Following $\mu \mathrm{CT}$ analysis, tissues were decalcified in $0.5 \mathrm{~mol} / \mathrm{L}$ EDTA ( $\mathrm{pH}$ 8.0) for $14 \mathrm{~d}$ at $4{ }^{\circ} \mathrm{C}$. Following decalcification, tissues were embedded in paraffinwax. Serial $5 \mu \mathrm{m}$ sagittal sections were performed at the distal femur tissues. Sections underwent H\&E staining. Sections were imaged using an Olympus (BX43) light microscope. Image J was used to quantify cortical widths and inflammatory areas. Maximum cortical width was evaluated at the distal ventral femur. Maximum cortical width was defined as maximum distance from cortical bone at the ventral surface to the beginning of contiguous marrow space. Furthermore, inflammatory infiltration areas were measured using ImageJ as the largest contiguous areas of inflammatory infiltrates at the ventral $1 / 3^{\text {rd }}$ of the femur epiphysis. Identification of inflammatory tissue eroding into the bone or marrow space in a mouse PJI model has been previously described (Thompson et al., 2018). Identification of inflammatory infiltrate was based on the following criteria: i) bone destruction, ii) fibrosis, iii) inflammatory infiltrate consisting of leukocytes representing chronic inflammation/osteomyelitis, as previously described (Thompson et al., 2018; Tiemann et al., 2014). Black outline of the ROIs of the ventral $1 / 3^{\text {rd }}$ of the epiphysis used to measure inflammatory areas are represented in Fig. 4a. Representation of the inflammatory infiltrate areas, used in the calculations, are demarcated by the orange outlines in Fig. 4a. Histological analyses were performed on all mice that were sacrificed at day 10 post-surgery $(n=5 \mathrm{implant}$, $n=9$ implant $+S$. aureus, $n=9$ implant $+\mathrm{fMLP}+S$. aureus). Representative histological images for each group were selected based on mean values for maximum cortical width at the distal femora as well as inflammatory infiltration areas.

\section{$\mu \mathrm{CT}$ assessment}

The distal $1 / 4^{\text {th }}$ of fixed femur tissues at the implant leg at day 10 post-surgery were assessed by $\mu \mathrm{CT}$ (Scanco, $\mu \mathrm{CT} 50)$. $\mu \mathrm{CT}$ was performed on all mice that were sacrificed at day 10 post-surgery $(n=5 \mathrm{implant}$, $n=9$ implant $+S$. aureus, $n=9$ implant $\mathrm{fMLP}+S$. aureus). $3 \mathrm{D}$ as well as mid-coronal $\mu \mathrm{CT}$ sections of the distal femur were evaluated. A maximum width of the distal femur was evaluated using a ventral view 3D $\mu \mathrm{CT}$ image and ImageJ. Increased maximum distal femur width has been previously used as a measure of infection in a mouse PJI model (Thompson et al., 2018). 3D images and mid-coronal $\mu \mathrm{CT}$ sections were used to evaluate the following scoring criteria: i) periosteal reaction; ii) focal cortical loss; iii) trabecular loss; iv) total PJI scores. Total PJI score for each femur was the addition of three scores: i) periosteal reaction; ii) focal cortical loss; iii) trabecular loss. These scores were determined on a scale of $0-2$, with 2 being the worst or most severe score. Subjective scoring criteria of bone were developed based on previous clinical radiographic evidence of PJI (Bauer et al., 2006) and mouse PJI model radiographic features and scoring (Carli et al., 2017). Criteria for the following periosteal reaction scores at the distal femur were as follows: 0 ) no or minimal periosteal reaction restricted to small regions; 1 ) moderate periosteal reaction with limited changes in cortical surface dimension and congruity; 2) severe and extensive spread of periosteal reaction with moderate to severe changes in cortical surface dimensions and congruity. Criteria for the focal cortical loss scores at the distal femur were as follows: 0) no or minimal areas of focal cortical loss; 1) definitive areas of focal cortical loss found in small regions of the distal femur containing near or full-thickness cortical bone loss; 2) severe focal cortical loss causing full-thickness cortical bone loss spread over large region(s) such as a femoral condyle. Criteria for trabecular loss score at the distal femur were as follows: 0) no or minimal loss of trabecular bone; 1) moderate loss of trabecular bone; 2) severe loss of trabecular bone. Scoring was performed by two blinded observers and an ICC was calculated to estimate inter-rater reliability. ICC values were as follows: i) periosteal reaction, ICC 0.969 (95\% CI $0.926-0.987)$; ii) focal cortical loss, ICC 0.986 (95\% CI 0.966-0.994); iii) trabecular loss, ICC 0.929 (95\% CI 0.832-0.970); iv) total PJI score, ICC 0.970 (95\% CI 0.928-0.987). Representative $\mu \mathrm{CT}$ images of each group were selected based on mean values for maximum distal femur width as well as scored parameters: periosteal reaction, focal cortical loss and trabecular loss.

\section{Weight-bearing assessment}

In addition to pain, impaired joint function is a common clinical symptomatic feature of PJI (Izakovicova et al., 2019). Weight-bearing at the implant leg was used as a measure of pain and joint function. Mice were assessed for weight-bearing at the right hindlimb at baseline (pre-surgery) and at day 10 post-surgery. Weight-bearing was assessed in all mice that were harvested at day 10 post-surgery ( $n=5 \mathrm{implant,} n=9 \mathrm{implant}+S$. aureus, $n=9 \mathrm{implant}$ $+\mathrm{fMLP}+\mathrm{S}$. aureus). Mouse weight-bearing was captured using iPhone $X$ (Apple) slow-motion video recording software, as previously described (Carli et al., 2017). Grading at the right hindlimb was as follows: full weight-bearing (3 points); partial weightbearing ( 2 points); toe-touch (1 point); non-weightbearing (0 points). Detailed scoring criteria are illustrated in Video 1 (available on journal website). Scoring was performed by two blinded observers and ICC was $0.972,95 \%$ CI 0.949-0.984.

\section{Pain behaviour assessment by von Frey filament testing}

One of the most common initial clinical findings or symptoms of a PJI is pain (Izakovicova et al., 2019; Tande and Patel, 2014). To measure pain behaviour in mice, mechanical allodynia was assessed using von 
Frey filament testing, as previously described (Im et al., 2010; Miller et al., 2012). Mice can demonstrate allodynia, or pain behaviour (demonstrated for instance by leg withdrawal), in response to a normal innocuous stimulus, through application of various levels of mechanical stimulus [von Frey filaments applied at the plantar hind paw (Deuis et al., 2017)]. Mice were placed on top of a metal mesh stand (IITC mesh stand part \#408, Woodland Hills, CA, USA) within a small, weighted plastic enclosure. Calibrated von Frey filaments (Stoelting ${ }^{\mathrm{TM}}$ Touch Test Sensory Probes, Fisher Scientific) ranging from filament forces of $2.44 \mathrm{~g}$ to $4.74 \mathrm{~g}$ were used. Filaments were applied to the plantar hind paw with a force requiring the filament to bow. Filaments were held at the plantar surface for $3 \mathrm{~s}$ or until a pain withdrawal response was displayed. A modified up-down method was used to calculate the force required to elicit withdrawal of the paw, which was quantified as PWT force (in g). Pain behaviour was assessed in all mice that were sacrificed at day 10 post-surgery ( $n=5 \mathrm{implant,} n=9 \mathrm{implant}+S$. aureus, $n=9 \mathrm{implant}$ $+\mathrm{fMLP}+\mathrm{S}$. aureus); baseline assessments for all these mice were performed as well.

\section{Weight}

Mice were assessed for body weight at baseline (pre-surgery) and at day 10 post-surgery. Weight measurements were taken to further evaluate a potential response of mice to both surgery and infection, as described previously (Carli et al., 2017), as well as to fMLP treatment. Weight was assessed in all mice that were sacrificed at day 10 post-surgery
( $n=5 \mathrm{implant,} n=9 \mathrm{implant}+S$. aureus, $n=9 \mathrm{implant}$ + fMLP + S. aureus). Weight was calculated in g using an electronic scale (Ohaus, Scout SPX, Parsippany, NJ, USA).

\section{Statistical analysis}

Statistical analysis for ICC was performed using SPSS statistics software version 27 . The remainder of statistical analyses were performed using Prism software version 8. Comparison between two groups was evaluated using an unpaired Student's $t$-test. Comparisons between more than two groups were evaluated with one-way ANOVA with post-hoc Tukey's multiple comparison test. Comparisons of more than two groups over time were evaluated with mixed-effects analysis with post-hoc Tukey's multiple comparison test. Data were presented as mean \pm SEM. Threshold for significance was set at $p<0.05$.

\section{Results}

\section{fMLP treatment increased neutrophil activity in} the knee joint

To assess whether fMLP could initiate and direct inflammatory responses toward the implant surgical site, even in the absence of injury and infection, mice received either fMLP or vehicle control in the right knee joint by intra-articular injection. Neutrophil response was assessed by in vivo BLI using luminol, which produces a bioluminescent signal in the presence of ROS catalysed by MPO in neutrophils (Gross et al., 2009; Tseng and Kung, 2013). BLI a
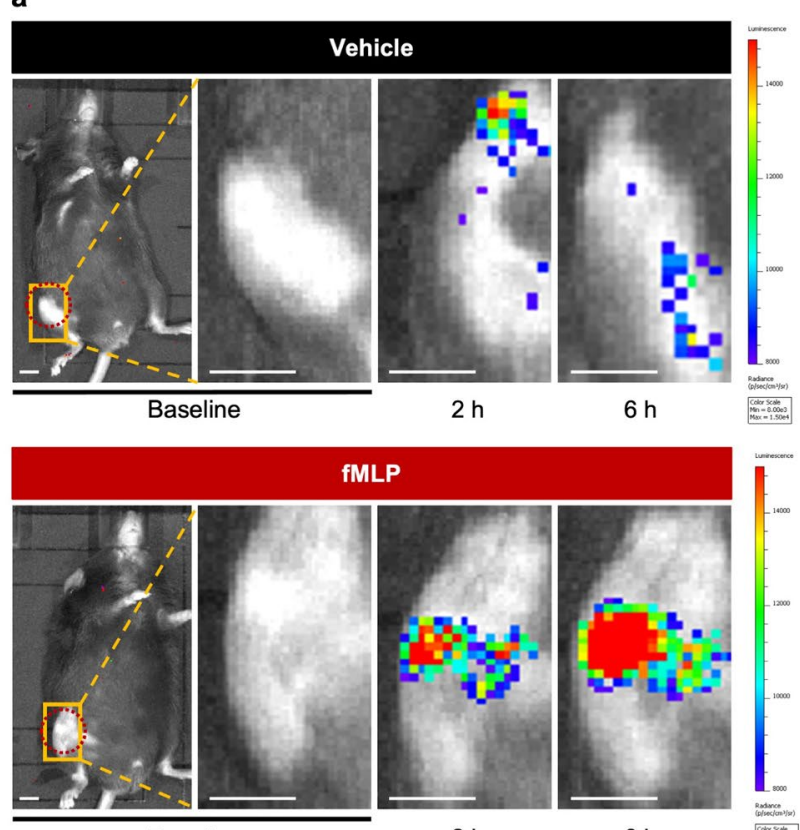

Baseline
fMLP

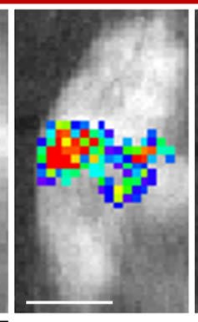

$2 \mathrm{~h}$ b

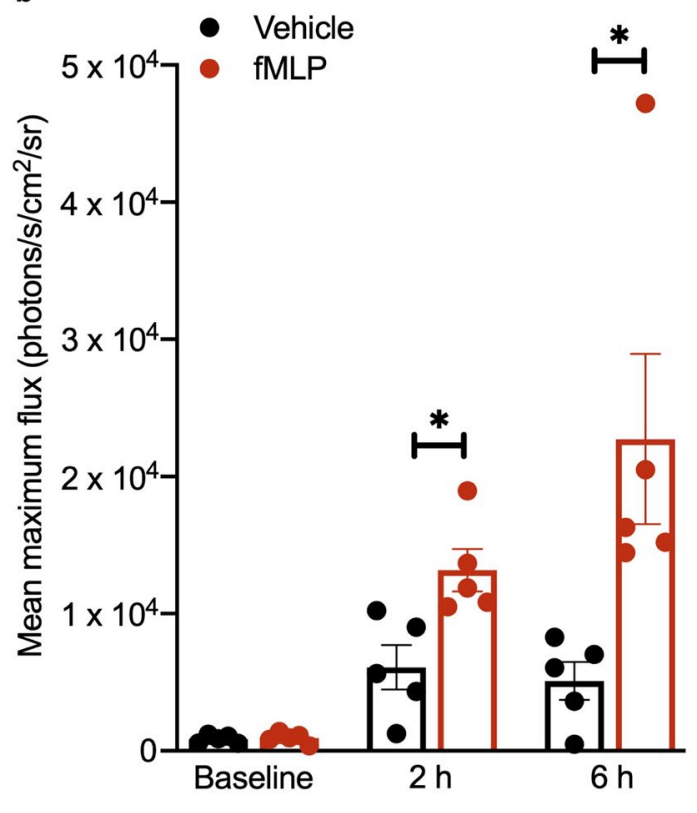

Fig. 1. fMLP increased neutrophil activity at the articular joint. (a) fMLP $(5 \mu \mathrm{g} / 5 \mu \mathrm{L})$ or vehicle $(5 \mu \mathrm{L}$ PBS $+25 \%$ DMSO) were injected into the right-knee joint. Neutrophil recruitment was assessed by BLI prior to knee injection (baseline) or at $2 \mathrm{~h}$ and $6 \mathrm{~h}$ post intra-articular knee injection and $8 \mathrm{~min}$ post intra-peritoneal luminol injection at each time point. Red-dashed circle represents ROI used for BLI quantification. (b) Corresponding tabulated data are shown as mean $\pm \operatorname{SEM}\left(n=5\right.$ mice/group, ${ }^{*} p<0.05$, Student's $t$-test). Scale bar: 4 mm. 
performed at baseline prior to injection demonstrated minimal to no neutrophil activity in the knee joint in either group. As compared to the mock group, mice receiving fMLP exhibited $\sim 2$-fold higher neutrophil response at the $2 \mathrm{~h}$ time point and 3 -fold higher neutrophil response at the $6 \mathrm{~h}$ time point as assessed by BLI (Fig. 1a,b). These results demonstrated that fMLP was able to mobilise and direct a neutrophil response toward the knee environment even in the absence of infection or surgery.

\section{fMLP treatment reduced $S$. aureus infection in a mouse model of PJI}

To show that an fMLP immunomodulator was able to reduce a PJI, an established PJI model with bioluminescent $S$. aureus was used, as described previously (Bernthal et al., 2010; Carli et al., 2017; Hegde et al., 2017a) and in Materials and Methods. In line with a previous report (Bernthal et al., 2010), bacterial-bioluminescence signal was significantly higher in infected mice as compared to non-infected mice, peaking at day 3 post-infection but declining over time and plateauing at day 7-10 post-infection (Fig. 2a,b). Importantly, infected mice receiving fMLP prior to infection had significantly reduced bacterial- bioluminescence signal at day 3 trending towards reduced signals at days 1 and 5, compared to mice receiving vehicle alone (Fig. $2 \mathbf{a}, \mathbf{b}, p<0.001$ ). Given that the peak infection occurred at day 3 in both mock and fMLP-treated mice, infected implants and tissue surrounding implants were collected and assessed for their bacterial infection burden by CFU analysis, as previously described (Goldufsky et al., 2015; Kroin et al., 2016; Kroin et al., 2018). CFU analyses of the knee-joint tissues at day 3 post-surgery revealed an approximate 2-Log order reduction in S. aureus bacterial numbers in the group that received fMLP, as compared to the infected group without fMLP (Fig. 2c, $p<0.01$ ). There also appeared to be a trend for $\mathrm{CFU}$ reduction on the implant itself in the group that received fMLP, but it did not reach statistical significance. Collectively, these data indicated that an fMLP immunomodulator was able to reduce acute $S$. aureus peak infection in the PJI model.

fMLP treatment reduced the pathological effects of $S$. aureus infection at the knee joint tissue and bone Bone destruction and joint dysfunction are common clinical signs of PJI (Bozhkova et al., 2020; Izakovicova et al., 2019; Lima et al., 2013). Knee joints and the a

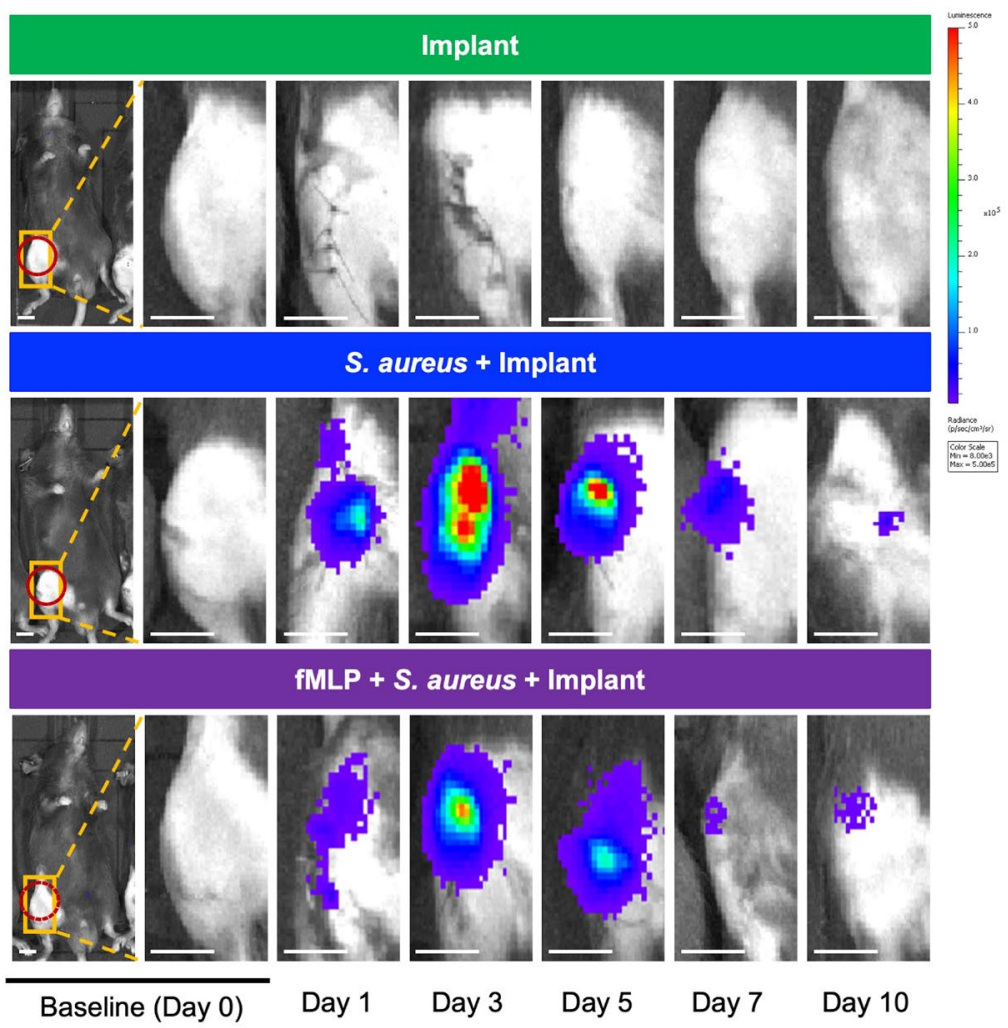

b

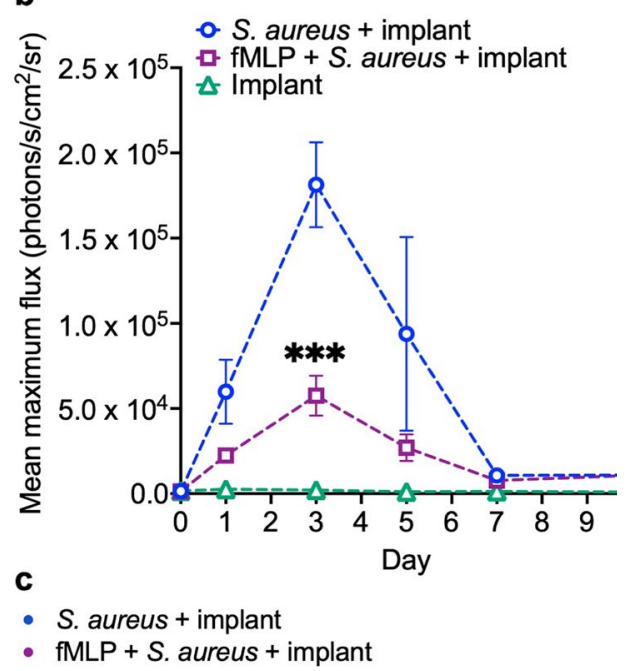

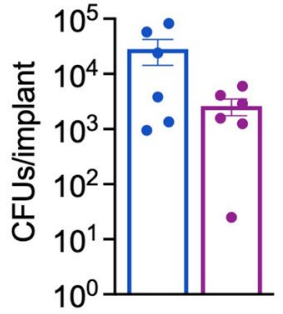

Fig. 2. fMLP treatment reduced S. aureus infection in a mouse model of PJI. (a) Mice received a surgically placed femoral implant and were treated with vehicle alone, $10^{3}$ Xen36 S. aureus or fMLP + Xen36 S. aureus . Infection burden was assessed by BLI performed at baseline as well as at days 1, 3, 5, 7 and 10 post-surgery and treatment. Red-dashed circle represents ROI used for BLI quantification. (b) Corresponding tabulated data for mean maximum flux (photons $\left./ \mathrm{s} / \mathrm{cm}^{2} / \mathrm{sr}\right)$ at the ROI are shown as mean \pm SEM $(n=5-15$ mice/ group, ${ }^{*} p<0.05$, mixed-effects analysis with post-hoc Tukey's multiple comparison test). (c) Quantification of bacterial CFUs at the knee-joint tissue and femoral implant at day 3. Data represented as mean \pm SEM $\left(n=6,{ }^{*} p<0.05\right.$, Student's $t$-test). Scale bar: $4 \mathrm{~mm}$. 
tissues surrounding the implants were collected at day 10 post-infection and evaluated for the impact of infection with or without fMLP treatment. A striking feature of knee joints in infected mice, particularly in the group without fMLP treatment, was their overall large size as compared to non-infected knee joints (Fig. $3 \mathbf{a}, \mathbf{b})$. This increased size was reflective of increased abscess formation within the knee-joint capsule. Infected mice without fMLP treatment had the largest knee-capsule width, which was significantly larger than non-infected mice (Fig. 3a, b, $p<0.01$ ). While the fMLP treatment group trended toward having a smaller knee capsule width as compared to mock-treated group, these differences did not reach statistical significance (Fig. 3a,b). Upon opening the knee-joint capsule and removing abscess debris, the distal femur surrounding the implant was evaluated (Fig. 3c). In all groups, there appeared to be some level of adhesive tissue to the distal femur, which was likely a consequence of tissue reaction to implant surgery. In the implant group, characteristic features of the distal femur, such as the femoral condyles were abundantly clear. Infected mice receiving fMLP also appeared to retain somewhat the natural morphology of the distal femur and femoral condyles; however, compared to the non-infected group, there appeared to be more adhesive tissue to the femoral condyles in this group. Mice infected without fMLP treatment had the highest level of adhesive tissue and abnormal morphology of the distal femur of any group. This was most clearly evidenced by a loss of rounded contours of the femoral condyles in the infected group without fMLP, as indicated by black arrows (Fig. 3c, black arrows).

To gain a better understanding of the effects of infection on the distal femur, with or without fMLP treatment, histological analysis of H\&E-stained sections of the distal femur was performed at day 10 post-infection. The fMLP-treated group had significantly smaller cortical bone width as compared to the infected group without fMLP treatment (Fig. $4 \mathbf{a}, \mathbf{b}$, indicated by black dotted lines in magnified regions in orange boxes). Increased cortical width was likely a result of stimulation of bone production (periosteal reaction) from the overlying periosteum due to chronic inflammation, as has been reported in the context of infection and inflammation (Rana et al., 2009). The implant group without infection had the smallest cortical width.

Inflammatory infiltrate has been found eroding into the distal femur in a mouse PJI model (Thompson et al., 2018), prompting the assessment of the pathological impact of infection with or without fMLP treatment on inflammatory responses and bone health. Data indicated that within the defined ROI in the ventral $1 / 3^{\text {rd }}$ of the femur epiphysis, the infected group without fMLP had the largest contiguous area of inflammatory cell and tissue infiltration, which was significantly higher than the fMLP-treated infected group (Fig. 4a,b, $p<0.05$, black arrow in a

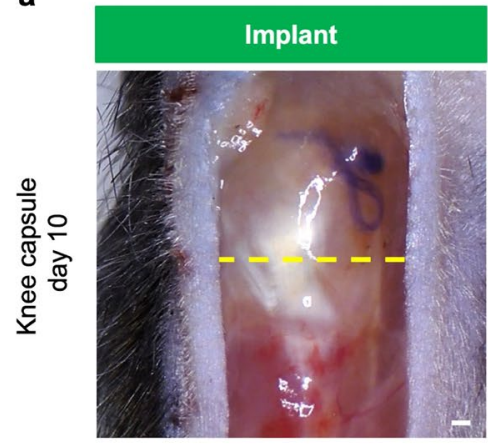

c

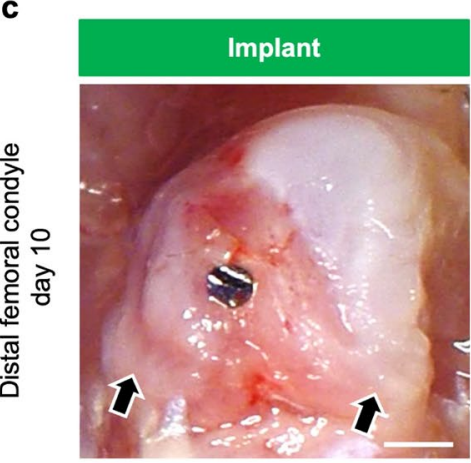

Implant $+S$. aureus

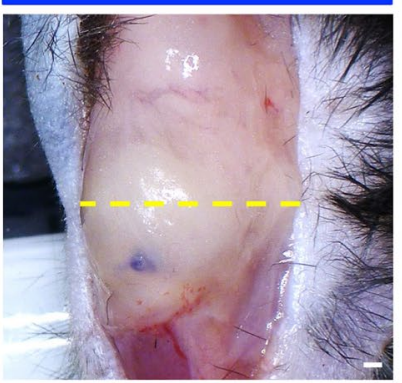

Implant + S. aureus

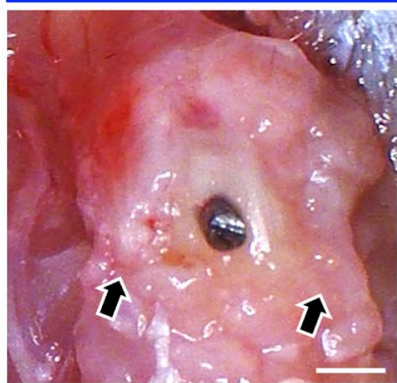

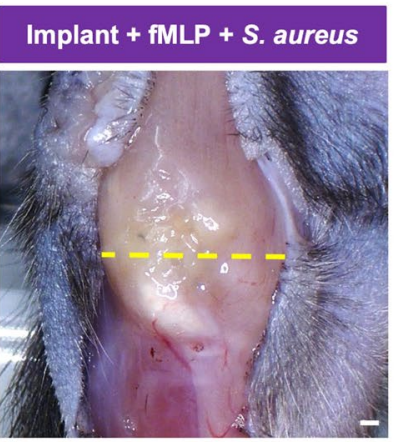

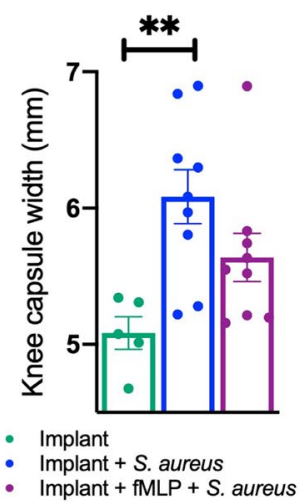

Implant + FMLP + $S$. aureus

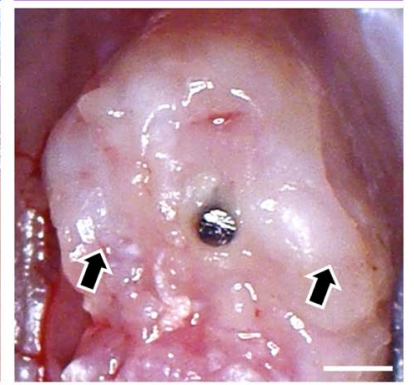

Fig. 3. fMLP reduced the pathological effects of infection at the knee-joint tissue surrounding the implant. (a) Gross morphological assessment was performed at the knee-joint capsule (knee capsule width in mm/ measure of intra-capsular abscess) and distal femur for cartilage/bone erosion surrounding the implant in animals sacrificed at day 10 post-surgery and treatment. Yellow dashed line represents maximum knee-capsule width. Black arrows represent region of the femoral condyles. (b) Knee-capsule width plotted as mean \pm SEM $\left(n=5-9,{ }^{* *} p<0.05\right.$, one-way ANOVA with post-hoc Tukey's multiple comparison test). Scale bar: $0.5 \mathrm{~mm}$. 
magnified regions in blue boxes). In contrast, the uninfected implant group had the smallest regions of inflammatory cell and tissue infiltrate, which was likely a result of surgery and implant placement (Fig. $4 \mathbf{a}, \mathbf{b})$. Within the ventral $1 / 3^{\text {rd }}$ of the femur epiphysis, the largest contiguous areas of inflammatory infiltrates were found at the bone-implant interface in all groups.

The pathological impact of infection with or without fMLP treatment on bone by $\mu \mathrm{CT}$ was assessed. Maximum width of the distal femur was measured on the ventral $\mu \mathrm{CT}$ 3D view. This was in particular used as a measure to quantify periosteal reaction, which would widen the femur width. Similar to the non-infected group, the fMLP-treated group had significantly reduced femoral width as compared to the infected group without fMLP (Fig. $5 \mathbf{a}, \mathbf{b}, p<0.01$, indicated by yellow dashed lines). 3D images of the side, dorsal and condyle views, as well as mid-coronal $\mu \mathrm{CT}$ sections were evaluated by two blinded observers and scored for i) periosteal reaction, ii) focal cortical loss, iii) trabecular loss and

a
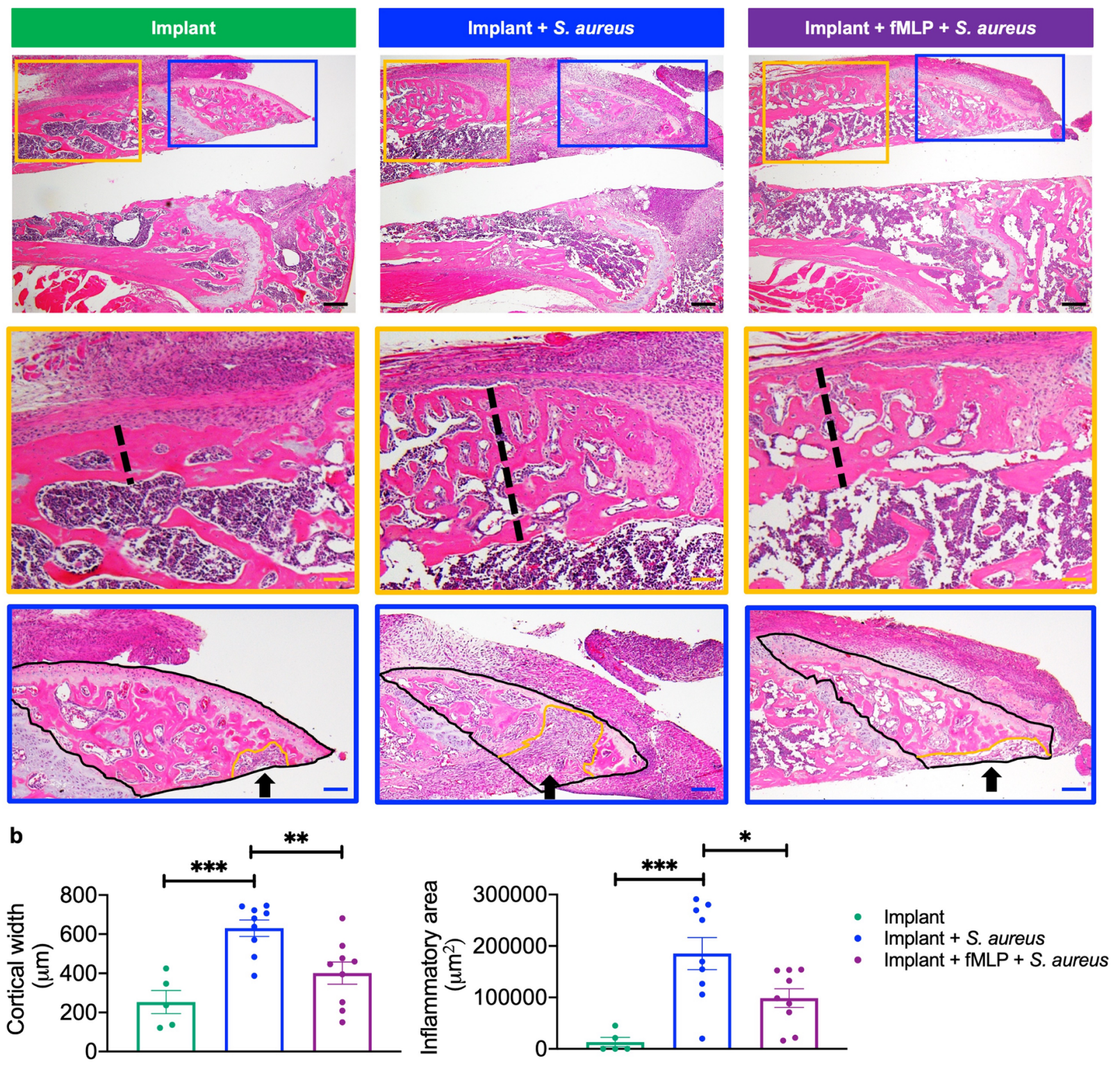

Fig. 4. fMLP protected against infection and inflammation-induced bone damage and changes around the implant. (a) At day 10 post-surgery and treatment, mice were sacrificed for histological assessment of the distal femur by H\&E staining. Two parameters identified in the distal femur were dramatically higher in the infection group without fMLP, maximum cortical width (measure of traditional cortical bone in addition to new adjacent bone formation formed by periosteal reaction, yellow magnification/black dashed line) and inflammatory infiltrate (blue magnification/black arrow). Inflammatory infiltrate was measured as the largest contiguous area of inflammatory infiltrate in the ventral $1 / 3^{\text {rd }}$ of the femur epiphysis. Within the blue magnification area, ROI for inflammatory infiltrate outlined with black solid line and inflammatory area outlined by an orange line. (b) Quantification of maximum cortical width and inflammatory infiltrate. Data represented as mean \pm SEM $\left(n=5-9,{ }^{*} p<0.05,{ }^{* *} p<0.01,{ }^{* * *} p<0.001\right.$, one-way ANOVA with post-hoc Tukey's multiple comparison test). Black scale bar: $200 \mu \mathrm{m}$; orange scale bar: $70 \mu \mathrm{m}$; blue scale bar: $85 \mu \mathrm{m}$. 
combination of all three parameters were indexed as a combined $\mu \mathrm{CT}$ PJI score.

As compared to the infected group treated with vehicle, the fMLP-treated group exhibited significantly reduced periosteal reaction (Fig. 5a,b, indicated by green arrows, $p<0.01)$ and focal cortical loss (Fig. 5a,b, indicated by purple arrows, $p<0.05)$. Trabecular loss was significantly higher in the infected group without fMLP, compared to the non-infected group $(p<0.001)$, with a trend towards
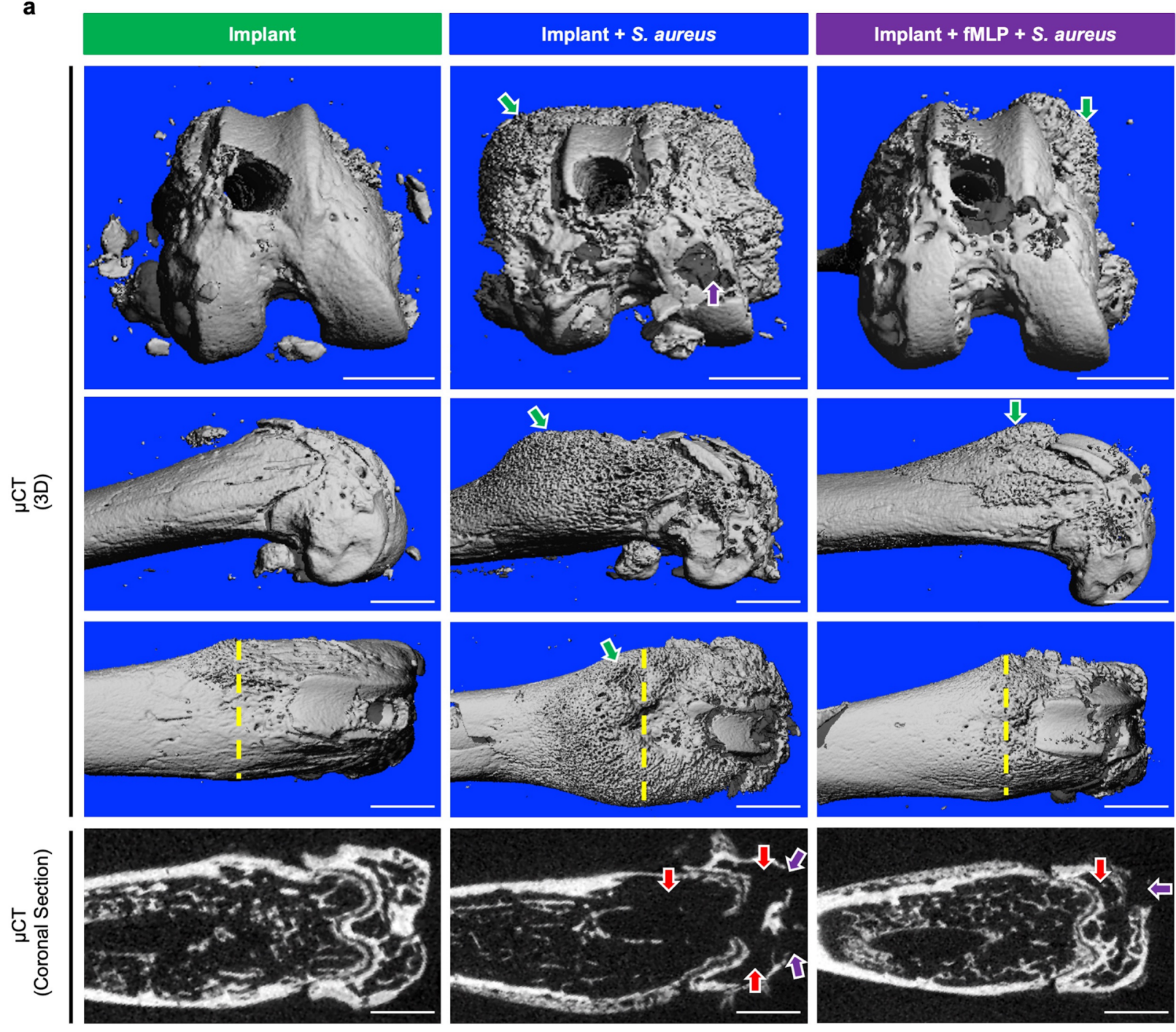

b
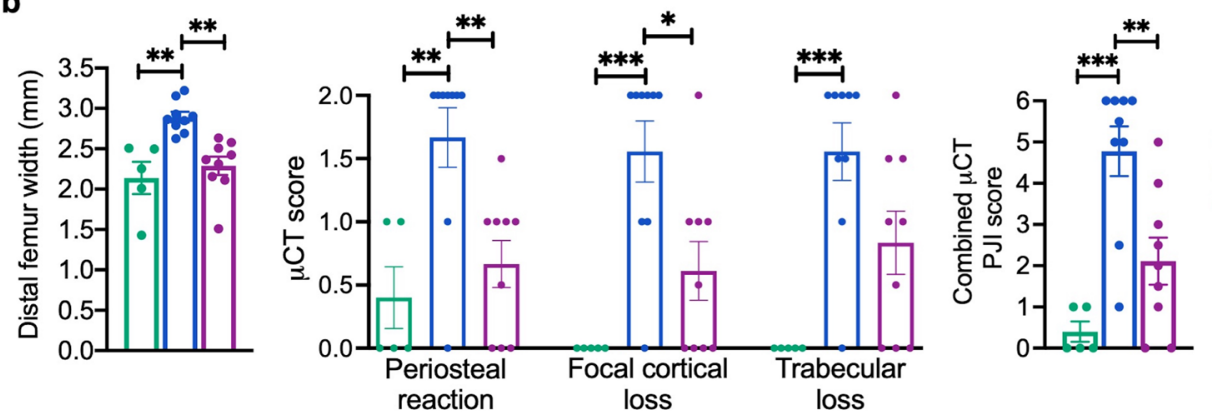

- Implant

Implant + S. aureus

- Implant + fMLP + S. aureus

Fig. 5. fMLP protected against infection and inflammation-induced bone damage and changes around the implant. Mice were sacrificed at day 10 post-surgery and treatment and femora at the implant sites were evaluated for pathological features as follows. (a) Distal femora were assessed by $\mu$ CT analysis on 3D imaging and mid-coronal sections. Green arrows point to periosteal reaction, purple arrows to focal cortical loss, red arrows to trabecular loss. Yellow-dashed line represents cortical width. (b) $\mu \mathrm{CT}$ quantification of maximum femur width in $\mathrm{mm}$ (based on ventral-view 3D image), periosteal reaction score, focal corticalloss score and trabecular-loss score, which were analysed using scoring criteria based on assessment of 3D images and mid-coronal sections by two blinded observers. Scoring criteria were quantified and combined as a single measure called combined $\mu$ CT PJI score. Data represented as mean \pm SEM $\left(n=5-9,{ }^{*} p<0.05\right.$, ${ }^{* *} p<0.01,{ }^{* * *} p<0.001$, one-way ANOVA with post-hoc Tukey's multiple comparison test). Scale bar: $1 \mathrm{~mm}$. 
higher values as compared to the infected group treated with fMLP, but this effect did not reach statistical significance (Fig. 5a,b, indicated by red arrows). When all three parameters were merged into a combined PJI $\mu \mathrm{CT}$ score, it was found that fMLP treatment significantly reduced the combined PJI $\mu C T$ pathology score as compared to the infected group without fMLP treatment (Fig. 5b, $p<0.01$ ).

\section{fMLP improved behavioural symptoms in a PJI mouse model}

Pain and joint dysfunction are common clinical symptom associated with PJI in patients (Bozhkova et al., 2020; Izakovicova et al., 2019; Lima et al., 2013). Pain behaviour was evaluated following two methods: weight-bearing on the right hindlimb (implant leg) and mechanical allodynia with von Frey filament testing, as previously described (Carli et al., 2017; Im et al., 2010; Miller et al., 2012). Weight-bearing was also used as an assessment for joint function (Carli et al., 2017). At baseline and prior to implant placement (day 0), mice in all groups exhibited a similar weight-bearing score and calculated withdrawal force threshold for evidence of mechanical allodynia (Fig. 6a,b). In contrast, at day 10 post-surgery, fMLP-treated infected mice exhibited a significantly improved weight-bearing score on the implant leg as compared to infected mice without fMLP (Fig. 6d, $p<0.001$ ). Furthermore, mice receiving $\mathrm{fMLP}$ also exhibited significantly improved (increased) withdrawal force threshold as compared to infected mice without fMLP treatment (Fig. 6e, $p<0.05)$. Collectively, these data indicated that fMLP treatment significantly improved the behavioural symptoms that are associated with PJI (Bozhkova et al., 2020; Izakovicova et al., 2019; Lima et al., 2013).

\section{fMLP treatment did not affect body weight in a mouse PJI model}

Prior to surgery, all groups had a similar average body weight (Fig. 6c). At day 10 post-surgery, all groups trended slightly toward having a lower weight; however, this was not statistically significant. Furthermore, at day 10 post-surgery, infected mice without fMLP treatment trended toward a slightly greater weight loss; however, this weight loss was not statistically significant between groups (Fig. 6f).

\section{Discussion}

PJI remains a devastating complication after arthroplasty, leading to pain, suffering, morbidity and a substantial economic burden (Kapadia et al., 2016; Kurtz et al., 2012). There is an urgent need for alternative and/or adjunct measures to antibiotic prophylaxis in addressing PJI. The present study assessed whether $\mathrm{AMLP}$, a potent immunomodulator that recruits and activates inflammatory leukocytes, particularly neutrophils, would be able to control PJI even in the absence of antibiotics. Data indicated that fMLP treatment significantly reduced $S$. aureus infection in an established PJI model. Furthermore, fMLP reduced infection-induced bone and tissue pathologies and, subsequently, infection-induced pain and weight-bearing behaviour in infected animals.

Although infection was significantly reduced in fMLP-treated mice, it was not completely abolished in this model. Whether this was due to low level of fMLP used or the inability of fMLP to engage the adaptive immune responses, which are also needed to fully control $S$. aureus infection (Lin et

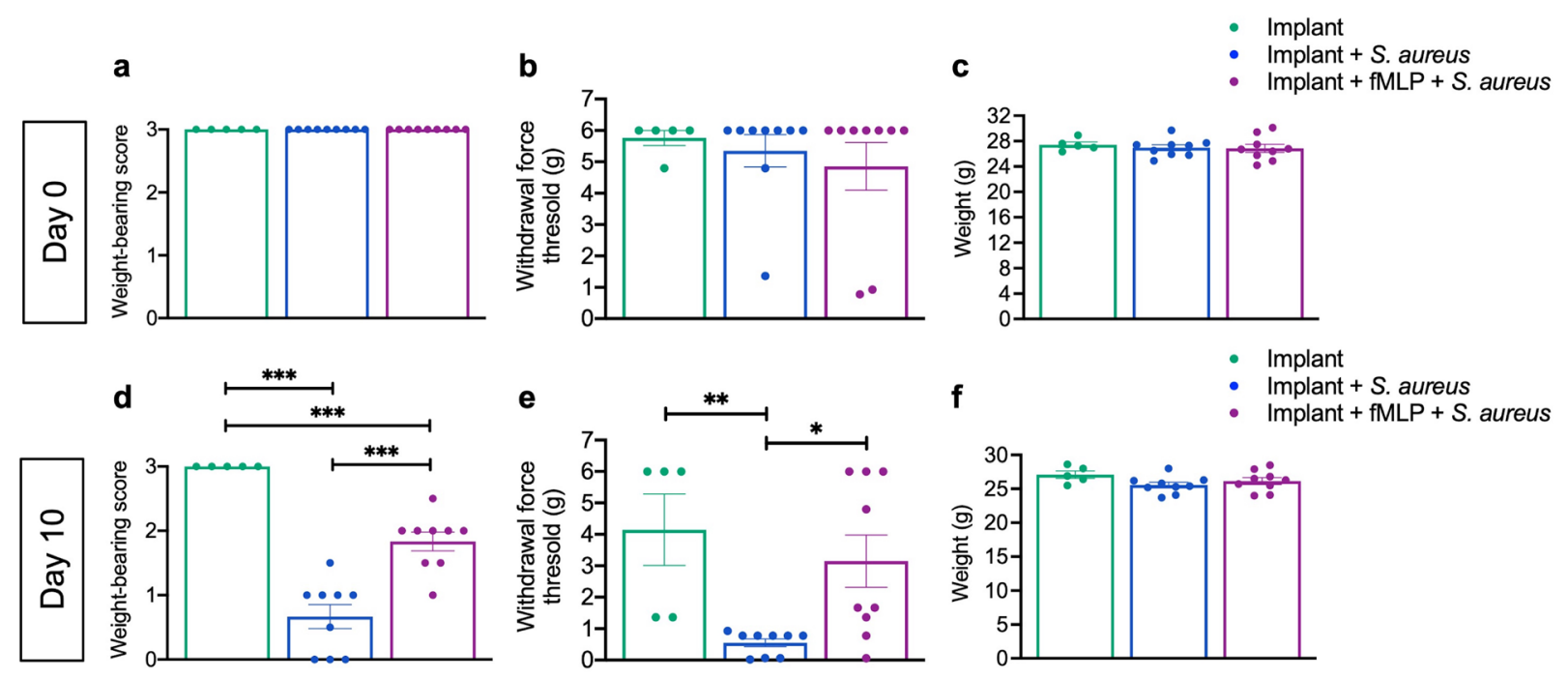

Fig. 6. fMLP treatment improved weight-bearing, decreased pain behaviour and had no effect on weight in a mouse model of PJI. Baseline assessment for (a) weight-bearing, (b) pain behaviour (mechanical allodynia) on von Frey filament testing and (c) body weight performed prior to surgery or treatment (day $0)$. Assessment of (d) weight-bearing, (e) pain behaviour and (f) body weight performed at day 10 postsurgery and treatment. Data represented as the mean $\pm \operatorname{SEM}\left(n=5-9,{ }^{*} p<0.05,{ }^{* *} p<0.01,{ }^{* * *} p<0.001\right.$, one-way ANOVA with post-hoc Tukey's multiple comparison test). 
al., 2009), remains to be investigated. Intriguingly, administration of systemic vancomycin prophylaxis or intra-articular vancomycin powder treatment alone also failed to completely eradicate $S$. aureus PJI in rats, although they were more effective in reducing infection when combined (Edelstein et al., 2017). Since antibiotics and immunomodulators (e.g. fMLP) combat infection through different mechanisms of action, combination therapy with both may also be more effective in eliminating a PJI. Future studies are needed to investigate whether fMLP in combination with prophylaxis or topical antibiotics would be more effective in controlling a PJI.

It is encouraging that $\mathrm{ALP}$ treatment reduced infection burden early after surgery and infection, given that bacteria have been shown to form biofilm on the implant surfaces early after infection (Carli et al., 2017; Lamret et al., 2020). Indeed, a high neutrophil to $S$. aureus ratio at the implant surface is a prognostic factor for reduced biofilm production (Ghimire et al., 2019). Bacterial pathogens, including $S$. aureus, are protected from neutrophil killing when embedded in fully mature biofilms (de Vor et al., 2020; Gunther et al., 2009; Kristian et al., 2008). Due to the concern of biofilm formation on the implant surface itself, coating the implant with fMLP might better mobilise neutrophil recruitment directly to the implant interface, thus increasing neutrophil to $S$. aureus ratio at the implant surface to prevent early biofilm formation. Future studies are needed to assess the impact of fMLP therapy (administered intra-articularly or by implant coating; alone or in combination with antibiotics) on biofilm production.

Inflammation and inflammatory responses are proportional to the bacterial burden and infection level and can culminate in severe tissue destruction (Bernthal et al., 2010; Carli et al., 2017). Chronic inflammation in the setting of infection can suppress osteoblast activity as well as enhance osteoclast activity and $S$. aureus infection can directly cause bone destruction, activate osteoclasts and inhibit osteoblasts leading to altered bone remodelling (Wright and Nair, 2010). Substantial evidence of inflammation and bone loss and destruction was found particularly in the infected group without fMLP, as assessed by gross morphology, $\mu \mathrm{CT}$ and histology. Furthermore, in the setting of osteomyelitis, periosteal reaction can occur through subperiosteal spread of inflammation, which in turn elevates and stimulates the periosteum to lay down new layers of bone (Rana et al., 2009). Consistent with this report, significant increases in inflammation and periosteal reaction were found in the mouse PJI model, as assessed by $\mu \mathrm{CT}$ and histological analyses. Importantly, fMLP lowered these infection-induced bone pathologies.

Common clinical signs of PJI include joint pain and joint dysfunction (Bozhkova et al., 2020; Izakovicova et al., 2019; Lima et al., 2013). Intriguingly, infected mice treated with fMLP exhibited significant reduction in pain behaviours and significant improvement in weight-bearing, further highlighting the positive impact of fMLP therapy in reducing PJI. Severe weight loss can be a sign of systemic infection with bacteria such as S. aureus (Wu et al., 2017). A slight trend towards weight loss was found in both infected and non-infected groups, although these differences did not reach statistical significance, suggesting that $S$. aureus infection in this model remained local. In line with the present study data, Carli et al. (2017), in a similar PJI S. aureus infection study, reported no significant differences in weights between the infected and non-infected groups, although both groups exhibited slightly lower weight at week 1 post-surgery.

There is minimal literature to date on the therapeutic use of fMLP. Interestingly, Shin et al. (2011) evaluated the impact of local treatment with fMLP (delivered in a hyaluronic acid gel carrier) in a rabbit calvaria defect model and demonstrated that fMLP promotes osteogenesis and bone formation at the defect site as compared to vehicle control. Of note, no evidence of increased inflammation was found at the defect site in rabbits treated with fMLP 4 weeks post treatment (Shin et al., 2011), suggesting that fMLP may have a positive effect on bone formation and healing after arthroplasty even in the absence of infection. Further studies should evaluate the positive or adverse impacts of local fMLP therapy on joint and surrounding tissue, as well as animal behaviour, in an uninfected cohort in a PJI model, to further lay the groundwork for its therapeutic use to combat PJI.

Sethi et al. (2015) reported that in rats with an S. aureus-contaminated surgically-placed tibialintramedullary implant, administration of CpG oligodeoxynucleotide, which is found in bacterial DNA and shown to trigger inflammatory responses, led to $\sim 67 \%$ reduction in infection burden early after infection but did not prevent the development of chronic infection over time. The present study results were in line with these findings showing that fMLP reduced early infection by a nearly 2-Log order at day 3 but did not completely abolish infection.

\section{Conclusions}

The present proof-of-concept study provided direct evidence in a mouse PJI model that fMLP immunomodulator was effective in reducing acute infection and protecting against infection-induced bone and tissue damage and associated pain. Immunomodulators such as fMLP may provide an alternative or adjunct therapeutic to antibiotics for reducing and/or treating PJI. Future studies should focus on optimisation of immunomodulator-based approaches such as fMLP dose assessment, implant coating with fMLP or combination of fMLP with prophylactic antibiotics or other immunomodulators. 


\section{Acknowledgements}

We would like to thank Ryan Ross and Rylan Martin for assistance with $\mu \mathrm{CT}$; Yumei Lei for assistance with histology; Lorenzo Girotto for assistance with surgery and tissue harvest. This work was supported by the NIH grant T32AR073157 to JH and MW; the Grainger Chair of the Rush Arthritis and Orthopedics Institute Fund to MW and NIH grants RO1AI150668 and RO1DK107713 to SHS.

\section{References}

Aggarwal VK, Bakhshi H, Ecker NU, Parvizi J, Gehrke T, Kendoff D (2014) Organism profile in periprosthetic joint infection: pathogens differ at two arthroplasty infection referral centers in Europe and in the United States. J Knee Surg 27: 399-406.

Allegranzi B, Zayed B, Bischoff P, Kubilay NZ, de Jonge S, de Vries F, Gomes SM, Gans S, Wallert ED, Wu X, Abbas M, Boermeester MA, Dellinger EP, Egger M, Gastmeier P, Guirao X, Ren J, Pittet D, Solomkin JS, Group WHOGD (2016) New WHO recommendations on intraoperative and postoperative measures for surgical site infection prevention: an evidence-based global perspective. Lancet Infect Dis 16: e288-e303.

Anesi JA, Blumberg EA, Abbo LM (2017) Perioperative antibiotic prophylaxis to prevent surgical site infections in solid organ transplantation. Transplantation 102: 21-34.

Balazovich KJ, Suchard SJ, Remick DG, Boxer L (1996) Tumor necrosis factor-alpha and FMLP receptors are functionally linked during FMLPstimulated activation of adherent human neutrophils. Blood 88: 690-696.

Bauer TW, Parvizi J, Kobayashi N, Krebs V (2006) Diagnosis of periprosthetic infection. J Bone Joint Surg Am 88: 869-882.

Becattini S, Taur Y, Pamer EG (2016) Antibioticinduced changes in the intestinal microbiota and disease. Trends Mol Med 22: 458-478.

Bernthal NM, Stavrakis AI, Billi F, Cho JS, Kremen TJ, Simon SI, Cheung AL, Finerman GA, Lieberman JR, Adams JS (2010) A mouse model of postarthroplasty Staphylococcus aureus joint infection to evaluate in vivo the efficacy of antimicrobial implant coatings. PLoS One 5: e12580. DOI: 10.1371/journal. pone.0012580.

Bernthal NM, Taylor BN, Meganck JA, Wang Y, Shahbazian JH, Niska JA, Francis KP, Miller LS (2014) Combined in vivo optical and $\mu \mathrm{CT}$ imaging to monitor infection, inflammation, and bone anatomy in an orthopaedic implant infection in mice. J Vis Exp 92: e51612. DOI: 10.3791/51612.

Bozhkova S, Suardi V, Sharma HK, Tsuchiya H, Del Sel H, Hafez MA, Benzakour T, Drago L, Romano CL (2020) The W.A.I.O.T. definition of peri-prosthetic joint infection: a multi-center, retrospective validation study. J Clin Med 9: 1965.DOI: 10.3390/jcm9061965.
Bratzler DW, Houck PM, Surgical Infection Prevention Guidelines Writers W, American Academy of Orthopaedic S, American Association of Critical Care N, American Association of Nurse A, American College of S, American College of Osteopathic S, American Geriatrics S, American Society of A, American Society of C, Rectal S, American Society of Health-System P, American Society of PeriAnesthesia N, Ascension H, Association of periOperative Registered N, Association for Professionals in Infection C, Epidemiology, Infectious Diseases Society of A, Medical L, Premier, Society for Healthcare Epidemiology of A, Society of Thoracic S, Surgical Infection S (2004) Antimicrobial prophylaxis for surgery: an advisory statement from the National Surgical Infection Prevention Project. Clin Infect Dis 38: 1706-1715.

Brinkmann V, Reichard U, Goosmann C, Fauler B, Uhlemann Y, Weiss DS, Weinrauch Y, Zychlinsky A (2004) Neutrophil extracellular traps kill bacteria. Science 303: 1532-1535.

Brubaker SW, Bonham KS, Zanoni I, Kagan JC (2015) Innate immune pattern recognition: a cell biological perspective. Annu Rev Immunol 33: 257290.

Campbell J, Filardo G, Bruce B, Bajaj S, Friel N, Hakimiyan A, Grumet R, Shafikhani S, Chubinskaya S, Cole BJ (2014) Salvage of contaminated osteochondral allografts: the effects of chlorhexidine on human articular chondrocyte viability. Am J Sports Med 42: 973-978.

Carli AV, Bhimani S, Yang X, Shirley MB, de Mesy Bentley KL, Ross FP, Bostrom MP (2017) Quantification of peri-implant bacterial load and in vivo biofilm formation in an innovative, clinically representative mouse model of periprosthetic joint infection. J Bone Joint Surg Am 99: e25. DOI: 10.2106/ JBJS.16.00815.

Corona A, Singer M (2010) Antibiotic prophylaxis to prevent surgical site infections: should it be prolonged or just perioperative and efficacious? Minerva Anestesiol 76: 389-391.

de Vor L, Rooijakkers SH, van Strijp JA (2020) Staphylococci evade the innate immune response by disarming neutrophils and forming biofilms. FEBS Lett 594: 2556-2569.

Derian CK, Santulli RJ, Rao PE, Solomon HF, Barrett JA (1995) Inhibition of chemotactic peptideinduced neutrophil adhesion to vascular endothelium by cAMP modulators. J Immunol 154: 308-317.

Deuis JR, Dvorakova LS, Vetter I (2017) Methods used to evaluate pain behaviors in rodents. Front Mol Neurosci 10: 284. DOI: 10.3389/fnmol.2017.00284.

Devosse T, Guillabert A, D'Haene N, Berton A, De Nadai P, Noel S, Brait M, Franssen J-D, Sozzani S, Salmon I (2009) Formyl peptide receptor-like 2 is expressed and functional in plasmacytoid dendritic cells, tissue-specific macrophage subpopulations, and eosinophils. J Immunol 182: 4974-4984.

Dorward DA, Lucas CD, Chapman GB, Haslett C, Dhaliwal K, Rossi AG (2015) The role of formylated 
peptides and formyl peptide receptor 1 in governing neutrophil function during acute inflammation. Am J Pathol 185: 1172-1184.

Dovi JV, Szpaderska AM, DiPietro LA (2004) Neutrophil function in the healing wound: adding insult to injury? Thromb Haemost 92: 275-280.

Edelstein AI, Weiner JA, Cook RW, Chun DS, Monroe E, Mitchell SM, Kannan A, Hsu WK, Stulberg SD, Hsu EL (2017) Intra-articular vancomycin powder eliminates methicillin-resistant $S$. aureus in a rat model of a contaminated intra-articular implant. J Bone Joint Surg Am 99: 232-238.

Edmiston CE, Jr., Bruden B, Rucinski MC, Henen C, Graham MB, Lewis BL (2013) Reducing the risk of surgical site infections: does chlorhexidine gluconate provide a risk reduction benefit? Am J Infect Control 41: S49-55.

Faure E, Mear JB, Faure K, Normand S, CouturierMaillard A, Grandjean T, Balloy V, Ryffel B, Dessein R, Chignard M, Uyttenhove C, Guery B, Gosset P, Chamaillard M, Kipnis E (2014) Pseudomonas aeruginosa type-3 secretion system dampens host defense by exploiting the NLRC4-coupled inflammasome. Am J Respir Crit Care Med 189: 799811.

Ghimire N, Pettygrove BA, Pallister KB, Stangeland J, Stanhope S, Klapper I, Voyich JM, Stewart PS (2019) Direct microscopic observation of human neutrophilstaphylococcus aureus interaction in vitro suggests a potential mechanism for initiation of biofilm infection on an implanted medical device. Infect Immun 87. e00745-19. DOI: 10.1128/IAI.00745-19.

Goldufsky J, Wood SJ, Jayaraman V, Majdobeh O, Chen L, Qin S, Zhang C, DiPietro LA, Shafikhani SH (2015) Pseudomonas aeruginosa uses T3SS to inhibit diabetic wound healing. Wound Repair Regen 23: 557-564.

Greif R, Akca O, Horn EP, Kurz A, Sessler DI, Outcomes Research G (2000) Supplemental perioperative oxygen to reduce the incidence of surgical-wound infection. N Engl J Med 342: 161-167.

Gross S, Gammon ST, Moss BL, Rauch D, Harding J, Heinecke JW, Ratner L, Piwnica-Worms D (2009) Bioluminescence imaging of myeloperoxidase activity in vivo. Nat Med 15: 455-461.

Gunther F, Wabnitz GH, Stroh P, Prior B, Obst U, Samstag Y, Wagner C, Hansch GM (2009) Host defence against Staphylococcus aureus biofilms infection: phagocytosis of biofilms by polymorphonuclear neutrophils (PMN). Mol Immunol 46: 1805-1813.

Guo H, Callaway JB, Ting JP (2015) Inflammasomes: mechanism of action, role in disease, and therapeutics. Nat Med 21: 677-687.

Hegde V, Dworsky EM, Stavrakis AI, Loftin AH, Zoller SD, Park HY, Richman S, Johansen D, Hu Y, Taylor JA, Hamad CD, Chun RF, Xi W, Adams JS, Bernthal NM (2017) Single-dose, preoperative vitamin-D supplementation decreases infection in a mouse model of periprosthetic joint infection. J Bone Joint Surg Am 99: 1737-1744.
Hornef MW, Wick MJ, Rhen M, Normark S (2002) Bacterial strategies for overcoming host innate and adaptive immune responses. Nat Immunol 3: 10331040.

Im HJ, Kim JS, Li X, Kotwal N, Sumner DR, van Wijnen AJ, Davis FJ, Yan D, Levine B, Henry JL, Desevre J, Kroin JS (2010) Alteration of sensory neurons and spinal response to an experimental osteoarthritis pain model. Arthritis Rheum 62: 29953005.

Izakovicova P, Borens O, Trampuz A (2019) Periprosthetic joint infection: current concepts and outlook. EFORT Open Rev 4: 482-494.

Jakobsson HE, Jernberg C, Andersson AF, SjolundKarlsson M, Jansson JK, Engstrand L (2010) Short-term antibiotic treatment has differing long-term impacts on the human throat and gut microbiome. PLoS One 5: e9836. DOI: 10.1371/journal.pone.0009836.

Janeway CA, Jr., Medzhitov R (2002) Innate immune recognition. Annu Rev Immunol 20: 197-216.

Kamath VH, Cheung JP, Mak KC, Wong YW, Cheung WY, Luk KD, Cheung KM (2016) Antimicrobial prophylaxis to prevent surgical site infection in adolescent idiopathic scoliosis patients undergoing posterior spinal fusion: 2 doses versus antibiotics till drain removal. Eur Spine J 25: 32423248.

Kapadia BH, Berg RA, Daley JA, Fritz J, Bhave A, Mont MA (2016) Periprosthetic joint infection. Lancet 387: 386-394.

Kawai T, Akira S (2011) Toll-like receptors and their crosstalk with other innate receptors in infection and immunity. Immunity 34: 637-650.

Khoshbin A, So JP, Aleem IS, Stephens D, Matlow AG, Wright JG, SickKids Surgical Site Infection Task F (2015) Antibiotic prophylaxis to prevent surgical site infections in children: a prospective cohort study. Ann Surg 262: 397-402.

Korpela K, Salonen A, Virta LJ, Kekkonen RA, Forslund K, Bork P, de Vos WM (2016) Intestinal microbiome is related to lifetime antibiotic use in Finnish pre-school children. Nat Commun 7: 10410. DOI: 10.1038/ncomms10410.

Kristian SA, Birkenstock TA, Sauder U, Mack D, Götz F, Landmann R (2008) Biofilm formation induces C3a release and protects Staphylococcus epidermidis from IgG and complement deposition and from neutrophil-dependent killing. J Infect Dis 197: 10281035.

Kroin JS, Buvanendran A, Li J, Moric M, Im HJ, Tuman KJ, Shafikhani SH (2015) Short-term glycemic control is effective in reducing surgical site infection in diabetic rats. Anesth Analg 6: 1289-1996.

Kroin JS, Buvanendran A, Tuman KJ, Kerns JM (2012) Effect of acute versus continuous glycemic control on duration of local anesthetic sciatic nerve block in diabetic rats. Reg Anesth Pain Med 37: 595600.

Kroin JS, Li J, Goldufsky JW, Gupta K, Moghtaderi M, Buvanendran A, Shafikhani SH (2016) Perioperative 
high inspired oxygen fraction therapy reduces surgical site infection with Pseudomonas aeruginosa in rats. J Med Microbiol 65: 738-744.

Kroin JS, Li J, Shafikhani S, Gupta KH, Moric M, Buvanendran A (2018) Local vancomycin effectively reduces surgical site infection at implant site in rodents. Reg Anesth Pain Med 43: 795-804.

Kurtz S, Ong K, Lau E, Mowat F, Halpern M (2007) Projections of primary and revision hip and knee arthroplasty in the United States from 2005 to 2030. J Bone Joint Surg Am 89: 780-785.

Kurtz SM, Lau E, Watson H, Schmier JK, Parvizi J (2012) Economic burden of periprosthetic joint infection in the United States. J Arthroplasty 27: 61-65.

Lai Y, Di Nardo A, Nakatsuji T, Leichtle A, Yang Y, Cogen AL, Wu ZR, Hooper LV, Schmidt RR, von Aulock S, Radek KA, Huang CM, Ryan AF, Gallo RL (2009) Commensal bacteria regulate Toll-like receptor 3-dependent inflammation after skin injury. Nat Med 15: $1377-1382$.

Lamret F, Colin M, Mongaret C, Gangloff SC, Reffuveille F (2020) Antibiotic tolerance of Staphylococcus aureus biofilm in periprosthetic joint infections and antibiofilm strategies. Antibiotics (Basel) 9: 547. DOI: 10.3390/antibiotics9090547.

Langdon A, Crook N, Dantas G (2016) The effects of antibiotics on the microbiome throughout development and alternative approaches for therapeutic modulation. Genome Med 8: 39. DOI: 10.1186/s13073-016-0294-z.

Li L, Chen K, Xiang Y, Yoshimura T, Su S, Zhu J, Bian Xw, Wang JM (2016) New development in studies of formyl-peptide receptors: critical roles in host defense. J Leukoc Biol 99: 425-435.

Lieberman JR, Hsu WK (2005) Prevention of venous thromboembolic disease after total hip and knee arthroplasty. J Bone Joint Surg Am 87: 2097-2112.

Lima AL, Oliveira PR, Carvalho VC, Saconi ES, Cabrita HB, Rodrigues MB (2013) Periprosthetic joint infections. Interdiscip Perspect Infect Dis 2013: 542796. DOI: 10.1155/2013/542796.

Lin L, Ibrahim AS, Xu X, Farber JM, Avanesian V, Baquir B, Fu Y, French SW, Edwards Jr JE, Spellberg B (2009) Th1-Th17 cells mediate protective adaptive immunity against Staphylococcus aureus and Candida albicans infection in mice. PLoS Pathog 5: e1000703. DOI: 10.1371/journal.ppat.1000703.

Lindsay W, Bigsby E, Bannister G (2011) Prevention of infection in orthopaedic joint replacement. J Perioper Pract 21: 206-209.

Madianos P, Bobetsis Y, Kinane D (2005) Generation of inflammatory stimuli: how bacteria set up inflammatory responses in the gingiva. J Clin Periodontol 32: 57-71.

Manning L, Metcalf S, Clark B, Robinson JO, Huggan P, Luey C, McBride S, Aboltins C, Nelson R, Campbell D, Solomon LB, Schneider K, Loewenthal M, Yates P, Athan E, Cooper D, Rad B, Allworth T, Reid A, Read K, Leung P, Sud A, Nagendra V, Chean R, Lemoh C, Mutalima N, Grimwade K, Sehu M, Torda A, Aung T, Graves S,
Paterson D, Davis J (2020) Clinical characteristics, etiology, and initial management strategy of newly diagnosed periprosthetic joint infection: a multicenter, prospective observational cohort study of 783 patients. Open Forum Infect Dis 7: ofaa068. DOI: $10.1093 /$ ofid/ofaa068.

Martinon F, Mayor A, Tschopp J (2009) The inflammasomes: guardians of the body. Annu Rev Immunol 27: 229-265.

Miller RE, Tran PB, Das R, Ghoreishi-Haack N, Ren D, Miller RJ, Malfait AM (2012) CCR2 chemokine receptor signaling mediates pain in experimental osteoarthritis. Proc Natl Acad Sci U S A 109: 2060220607.

Mohamed MF, Wood SJ, Roy R, Reiser J, Kuzel TM, Shafikhani SH (2021) Pseudomonas aeruginosa ExoT induces G1 cell cycle arrest in melanoma cells. Cell Microbiol: e13339. DOI: 10.1111/cmi.13339.

Nagao M, Hamilton JL, Kc R, Berendsen AD, Duan X, Cheong CW, Li X, Im H-J, Olsen BR (2017) Vascular endothelial growth factor in cartilage development and osteoarthritis. Sci Rep 7: 13027. DOI: 10.1038/ s41598-017-13417-w.

Panahi P, Stroh M, Casper DS, Parvizi J, Austin MS (2012) Operating room traffic is a major concern during total joint arthroplasty. Clin Orthop Relat Res 470: 2690-2694.

Panaro M, Mitolo V (1999) Cellular responses to FMLP challenging: a mini-review. Immunopharmacol Immunotoxicol 21: 397-419.

Parvizi J, Shohat N, Gehrke T (2017) Prevention of periprosthetic joint infection: new guidelines. Bone Joint J 99: 3-10.

Pelt CE, Grijalva R, Anderson L, Anderson MB, Erickson J, Peters CL (2014) Two-stage revision TKA is associated with high complication and failure rates. Adv Orthop 2014: 659047. DOI: 10.1155/2014/659047.

Pulido L, Ghanem E, Joshi A, Purtill JJ, Parvizi J (2008) Periprosthetic joint infection: the incidence, timing, and predisposing factors. Clin Orthop Relat Res 466: 1710-1715.

Rana RS, Wu JS, Eisenberg RL (2009) Periosteal reaction. AJR Am J Roentgenol 193: W259-272.

Raoof M, Zhang Q, Itagaki K, Hauser CJ (2010) Mitochondrial peptides are potent immune activators that activate human neutrophils via FPR-1. J Trauma 68: 1328-1332.

Sabroe I, Prince LR, Jones EC, Horsburgh MJ, Foster SJ, Vogel SN, Dower SK, Whyte MK (2003) Selective roles for Toll-like receptor (TLR)2 and TLR4 in the regulation of neutrophil activation and life span. J Immunol 170: 5268-5275.

Sampson TR, Debelius JW, Thron T, Janssen S, Shastri GG, Ilhan ZE, Challis C, Schretter CE, Rocha S, Gradinaru V, Chesselet M-F, Keshavarzian A, Shannon KM, Krajmalnik-Brown R, Wittung-Stafshede P, Knight R, Mazmanian SK (2016) Gut microbiota regulate motor deficits and neuroinflammation in a model of Parkinson's disease. Cell 167: 1469-1480.

Schroder K, Tschopp J (2010) The inflammasomes. Cell 140: 821-832. 
Segawa H, Tsukayama DT, Kyle RF, Becker DA, Gustilo RB (1999) Infection after total knee arthroplasty. A retrospective study of the treatment of eighty-one infections. J Bone Joint Surg Am 81: 1434-1445.

Sengeløv H, Boulay F, Kjeldsen L, Borregaard N (1994) Subcellular localization and translocation of the receptor for $\mathrm{N}$-formylmethionyl-leucylphenylalanine in human neutrophils. Biochem J 299: 473-479.

Sethi S, Thormann U, Sommer U, Stotzel S, Mohamed W, Schnettler R, Domann E, Chakraborty T, Alt V (2015) Impact of prophylactic CpG oligodeoxynucleotide application on implantassociated Staphylococcus aureus bone infection. Bone 78: 194-202.

Sewick A, Makani A, Wu C, O’Donnell J, Baldwin KD, Lee GC (2012) Does dual antibiotic prophylaxis better prevent surgical site infections in total joint arthroplasty? Clin Orthop Relat Res 470: 2702-2707.

Shafikhani SH, Engel J (2006) Pseudomonas aeruginosa type III-secreted toxin ExoT inhibits hostcell division by targeting cytokinesis at multiple steps. Proc Natl Acad Sci U S A 103: 15605-15610.

Shafikhani SH, Morales C, Engel J (2008) The Pseudomonas aeruginosa type III secreted toxin ExoT is necessary and sufficient to induce apoptosis in epithelial cells. Cellular microbiology 10: 994-1007.

Shin MK, Jang YH, Yoo HJ, Kang DW, Park MH, Kim MK, Song JH, Kim SD, Min G, You HK (2011) N-formyl-methionyl-leucyl-phenylalanine (fMLP) promotes osteoblast differentiation via the $\mathrm{N}$-formyl peptide receptor 1-mediated signaling pathway in human mesenchymal stem cells from bone marrow. J Biol Chem 286: 17133-17143.

Sidhwa F, Itani KM (2015) Skin preparation before surgery: options and evidence. Surg Infect (Larchmt) 16: 14-23.

Stannard JP, Volgas DA, McGwin G, 3rd, Stewart RL, Obremskey W, Moore T, Anglen JO (2012) Incisional negative pressure wound therapy after high-risk lower extremity fractures. J Orthop Trauma 26: 37-42.

Takeuchi O, Akira S (2010) Pattern recognition receptors and inflammation. Cell 140: 805-820.

Tan TL, Maltenfort MG, Chen AF, Shahi A, Higuera CA, Siqueira M, Parvizi J (2018) Development and evaluation of a preoperative risk calculator for periprosthetic joint infection following total joint arthroplasty. J Bone Joint Surg Am 100: 777-785.

Tande AJ, Patel R (2014) Prosthetic joint infection. Clin Microbiol Rev 27: 302-345.

Thompson JM, Miller RJ, Ashbaugh AG, Dillen CA, Pickett JE, Wang Y, Ortines RV, Sterling RS, Francis KP, Bernthal NM, Cohen TS, Tkaczyk C, Yu L, Stover CK, DiGiandomenico A, Sellman BR, Thorek DL, Miller LS (2018) Mouse model of gram-negative prosthetic joint infection reveals therapeutic targets. JCI Insight 3. e121737. DOI: 10.1172/jci.insight.121737.

Tiemann A, Hofmann GO, Krukemeyer MG, Krenn V, Langwald S (2014) Histopathological osteomyelitis evaluation score (HOES) - an innovative approach to histopathological diagnostics and scoring of osteomyelitis. GMS Interdiscip Plast Reconstr Surg DGPW 3: Doc08. DOI: 10.3205/iprs000049.

Tolle L, Yu F-s, Kovach MA, Ballinger MN, Newstead MW, Zeng X, Nunez G, Standiford TJ (2015) Redundant and cooperative interactions between TLR5 and NLRC4 in protective lung mucosal immunity against Pseudomonas aeruginosa. J Innate Immun 7: 177-186.

Tsai Y, Chang CH, Lin YC, Lee SH, Hsieh PH, Chang Y (2019) Different microbiological profiles between hip and knee prosthetic joint infections. J Orthop Surg (Hong Kong) 27: 2309499019847768. DOI: $10.1177 / 2309499019847768$.

Tseng JC, Kung AL (2013) In vivo imaging method to distinguish acute and chronic inflammation. J Vis Exp: 50690. DOI: 10.3791/50690.

Wood SJ, Goldufsky J, Shafikhani SH (2015a) Pseudomonas aeruginosa ExoT induces atypical anoikis apoptosis in target host cells by transforming Crk adaptor protein into a cytotoxin. PLoS Pathog 11: e1004934. DOI: 10.1371/journal.ppat.1004934.

Wood SJ, Goldufsky JW, Bello D, Masood S, Shafikhani SH (2015b) Pseudomonas aeruginosa ExoT induces mitochondrial apoptosis in target host cells in a manner that depends on its GTPase-activating protein (GAP) domain activity. J Biol Chem 290: 29063-29073.

Wright JA, Nair SP (2010) Interaction of Staphylococci with bone. Int J Med Microbiol 300: 193-204.

Wu D, Zhou S, Hu S, Liu B (2017) Inflammatory responses and histopathological changes in a mouse model of Staphylococcus aureus-induced bloodstream infections. J Infect Dev Ctries 11: 294-305.

Yassour M, Vatanen T, Siljander H, Hamalainen AM, Harkonen T, Ryhanen SJ, Franzosa EA, Vlamakis H, Huttenhower C, Gevers D, Lander ES, Knip M, Group DS, Xavier RJ (2016) Natural history of the infant gut microbiome and impact of antibiotic treatment on bacterial strain diversity and stability. Sci Transl Med 8: 343ra381. DOI: 10.1126/ scitranslmed.aad0917.

\section{Discussion with Reviewers}

Marloes Hofstee: A relative low number of S. aureus was applied as inoculum. What was the rationale behind this? And would the effectiveness of fMLP have been different if more $S$. aureus had been used instead? Also, it would be interesting to see whether fMLP can have a positive effect on a chronic PJI mouse model (large CFU counts at later time points) with a study duration of 3 or even 4 weeks.

Authors: Bernthal et al. (2014) and Hedge et al. (2017) used and validated $1 \times 10^{3} \mathrm{CFU}$ of $S$. aureus in the same mouse PJI model. Bernthal et al. (2010) evaluated inoculation with $S$. aureus at $5 \times 10^{2}, 5 \times 10^{3}$ and $5 \times 10^{4}$ CFUs in the same mouse PJI model. Use of $5 \times 10^{3}$ 
and $5 \times 10^{4}$ CFUs produced a substantial and rapid purulent joint infection but a milder clinical course of infection developed over time at $5 \times 10^{2} \mathrm{CFU}$. The authors further commented that the lower inoculation dose was more translatable to the chronic and persistent infection, as seen in clinical PJI (Bernthal et al., 2010). These reports were the reason for choosing $1 \times 10^{3} \mathrm{CFU}$ in the present study. As for evaluation of the long-term impact of fMLP therapy, it would be very interesting to evaluate whether fMLP could have a positive effect on a chronic PJI mouse model (high CFU counts at later time points) with a study duration of 3 or even 4 weeks. We are very much interested in addressing these interesting questions.

Marloes Hofstee: In the Discussion, it was mentioned that fMLP may be unable to engage the adaptive immune responses. Would it be an option to combine fMLP with an immunomodulator that targets the adaptive immune responses?

Authors: We agree with the reviewer and we are very much interested in determining the direct versus indirect effects of fMLP on adaptive immunity branch to assess whether combining this fMLP with another immunomodulator that can directly act on adaptive immune responses could improve PJI infection control.

Benjamin Ricciardi: The present study reflected therapeutic treatment of implant-associated infection but the gold-standard therapy (systemic antibiotics) was not included as a treatment group. Do you think the described treatment would have a synergistic effect with systemic antibiotic treatment or would they not complement each other and why?

Authors: We believe that, in combination, antibiotics and fMLP may work synergistically or additively in controlling an infection. Our reasoning is that antibiotics kill pathogenic bacterial by various mechanisms (depending on the antibiotics) that are different from the antimicrobial mechanisms that are at the disposal of innate immune leukocytes. Therefore, we should get better a outcome when antibiotics are combined with fMLP with respect to infection control. Of course, future studies are needed to directly examine this hypothesis.
Reviewer: Please clarify the expected impact of fMLP on non-infected joints. Is there any concern that elevated infiltration of neutrophils could negatively affect joint health?

Authors: Although fMLP is likely to transiently increase pro-inflammatory cytokine production in a knee joint, it is unlikely that fMLP treatment would lead to a chronic inflammatory environment. As damaging as sustained and chronic inflammation is on tissue and bone health, inflammatory responses during the acute phase of healing early after injury are essential for bone and tissue repair and without inflammatory responses bone will not heal (Phillips, 2005; Remedios, 1999, additional references). Interestingly, Shin et al. (2011) demonstrated that local fMLP treatment supports osteogenesis and promotes bone formation at a calvaria defect in rabbits in the absence of infection. Moreover, local treatment with fMLP does not display evidence of chronic inflammation or inflammatory bone damage (Shin et al., 2011). In the future, the positive and/or adverse impacts of fMLP on bone and tissue health in the absence of infection will be investigated using the model described in the present study.

\section{Additional References}

Phillips A (2005) Overview of the fracture healing cascade. Injury 36: S5-S7.

Remedios (1999) Bone and bone healing. Vet Clin North Am Small Anim Pract 29: 1029-1044.

Editor's note: The Scientific Editor responsible for this paper was Fintan Moriarty.

Video on journal website. Weight-bearing assessment. Scoring for weight-bearing at implant leg (right hindlimb) performed on video analysis with scores ranging from 0-3. Score 3: full weight-bearing; score 2: partial weight-bearing; score 1: toe-touch; score 0: non-weight-bearing. 